\title{
Evaluation of Factors Affecting the Timing Capabilities of the MC3858 Sprytron
}

SAND92- 183 T? DQEI 1

UNCLASSIF IEII

\author{
Stephen R. Lee, Charlotte J. Barclay
}

\section{Prepared by}

Sandia National Laboratories

Albuquerque, New Mexico 87185 and Livermore, California 94550

for the United States Department of Energy

under Contract DE-AC04-76DP00789

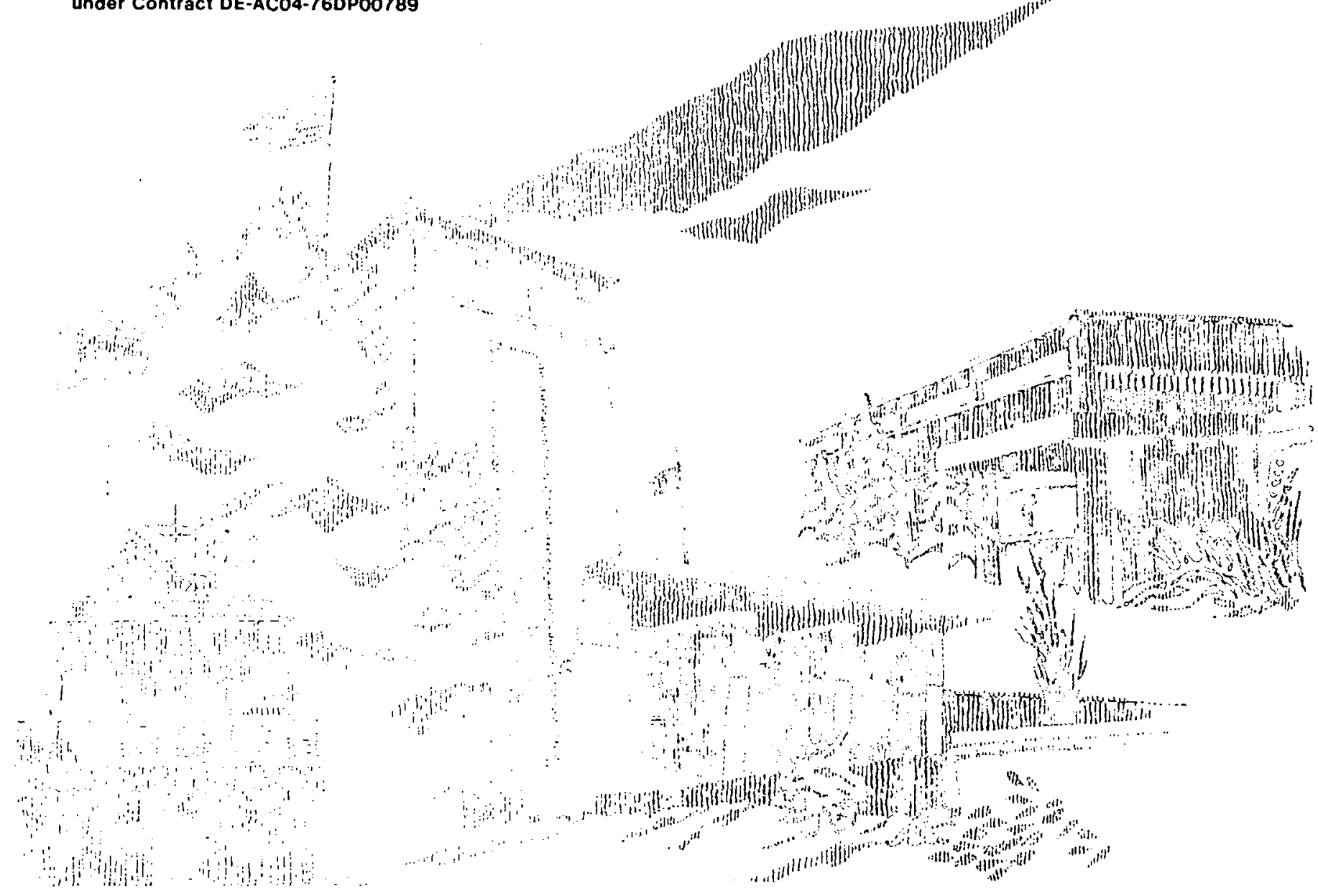


Issued by Sandia National Laboratories, operated for the United States Department of Energy by Sandia Corporation.

NOTICE: This report was prepared as an account of work sponsored by an agency of the United States Government. Neither the United States Government nor any agency thereof, nor any of their employees, nor any of their contractors, subcontractors, or their employees, makes any warranty, express or implied, or assumes any legal liability or responsibility for the accuracy, completeness, or usefulness of any information, apparatus, product, or process disclosed, or represents that its use would not infringe privately owned rights. Reference herein to any specific commercial product, process, or service by trade name, trademark, manufacturer, or otherwise, does not necessarily constitute or imply its endorsement, recommendation, or favoring by the United States Government, any agency thereof or any of their contractors or subcontractors. The views and opinions expressed herein do not necessarily state or reflect those of the United States Government, any agency thereof or any of their contractors.

Printed in the United States of America. This report has been reproduced directly from the best available copy.

Available to DOE and DOE contractors from

Office of Scientific and Technical Information

PO Box 62

Oak Ridge, TN 37831

Prices available from (615) 576-8401, FTS 626-8401

Available to the public from

National Technical Information Service

US Department of Commerce

5285 Port Royal Rd

Springfield, VA 22161

NTIS price codes

Printed copy: A03

Microfiche copy: A01 


\title{
EVALUATION OF FACTORS AFFECTING THE TIMING CAPABILITIES OF THE MC3858 SPRYTRON
}

\author{
Stephen R. Lee and Charlotte J. Barclay \\ Special Applications Division \\ Sandia National Laboratories \\ Albuquerque, New Mexico 87185
}

\begin{abstract}
The switch delay time of the MC3858 sprytron was measured using a test matrix consisting of 36 different trigger circuit configurations. The test matrix allowed the measurement of switch delay times for peak trigger voltages ranging from $47 \mathrm{~V}$ to $1340 \mathrm{~V}$ and for stored trigger energies ranging from $0.023 \mathrm{~mJ}$ to $2.7 \mathrm{~mJ}$. The average switch delay time was independent of peak trigger voltage above approximately $800 \mathrm{~V}$. Similarly, the average switch delay was independent of trigger stored energy above approximately $0.5 \mathrm{~mJ}$. Below these saturation values, the average switch delay increases rapidly with decreasing trigger voltage or energy.
\end{abstract}

In contrast to the average switch delay time, the shot-to-shot variability in switch delay time does not appear to be strongly affected by peak trigger voltage as long as the trigger voltage is greater than $100 \mathrm{~V}$. Below $100 \mathrm{~V}$, the variability in switch delay time rises rapidly due to failure of the trigger to undergo immediate high voltage breakdown when trigger voltage is applied. Above $100 \mathrm{~V}$, the variability in switch delay is primarily a function of the trigger stored energy. The maximum variation in switch delay decreases from $30 \mathrm{~ns}$ at $0.1 \mathrm{~mJ}$ to $6 \mathrm{~ns}$ at $2.7 \mathrm{~mJ}$.

The effect of an abnormally-high-resistance trigger probe on switch delay time was also investigated. It was found that a high-resistance probe behaved as a second overvoltage gap in the trigger circuit. Operation with a peak trigger voltage greater than the breakdown voltage of this second gap yielded delay times comparable to operation with a normal trigger. Operation with a peak trigger voltage less than the breakdown voltage of this second gap increased the switch delay time by an amount comparable to the time required to ramp the trigger circuit output up to the breakdown voltage of the second gap.

Finally, the effect that varying the bias voltage applied to the sprytron has on switch delay time was measured. For the trigger configurations used here, the switch delay time did not appear to depend on bias voltage for bias voltages between $725 \mathrm{~V}$ and $2420 \mathrm{~V}$. 


\section{CONTENTS}

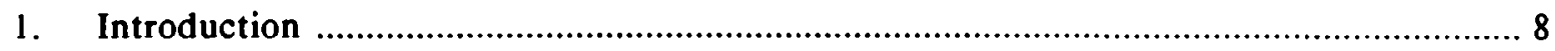

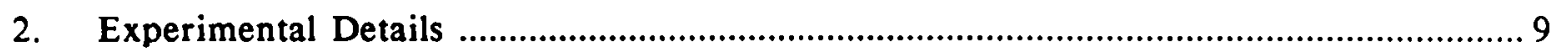

2.1 Test Circuit and Test Instrumentation ........................................................ 9

2.2 Technique Used to Determine Switch Delay Time ......................................... 9

2.3 Ramp Rate Capability of Test Circuit vs. Triggering Capacitance ....................11

2.4 Overvoltage Gap Breakdown Voltage vs. Ramp Rate ....................................11

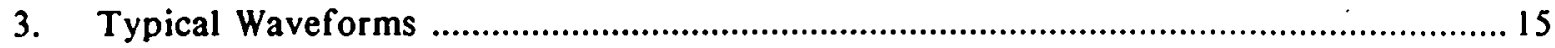

3.1 Typical Waveforms for High Trigger Energy and Voltage ...............................15

3.2 Typical Waveforms for Medium Trigger Energy and Voltage .......................... 22

3.3 Typical Waveforms for Low Trigger Energy and Voltage ...............................22

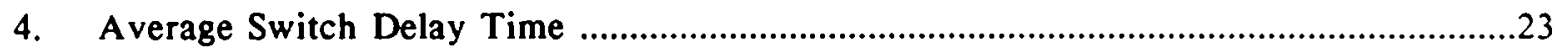

4.1 Average Switch Delay vs Peak Trigger Voltage ............................................23

4.2 Average Switch Delay vs Trigger Stored Energy ..........................................23

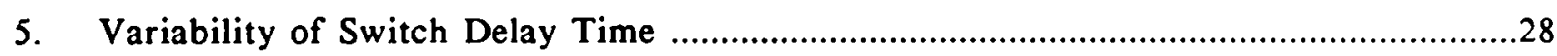

5.1 Variation in Switch Delay vs Average Switch Delay ........................................28

$5.2 \quad$ Variation in Switch Delay vs Peak Trigger Voltage ..........................................28

5.3 Variation in Switch Delay vs Trigger Stored Energy .......................................... 28

6. Trigger Resistance Effect on Switch Delay .............................................................33

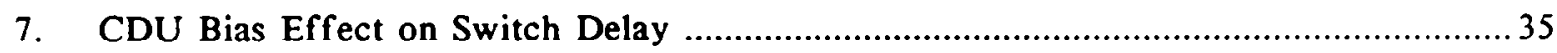

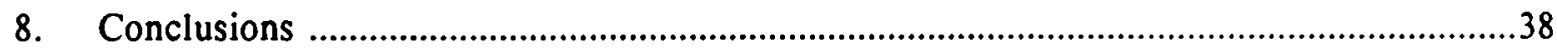




\section{FIGURES}

1. Test circuit used to study factors affecting switch tube timing. ...........................10

2. Trigger capacitor voltage ramp rate versus trigger circuit FET gate voltage for trigger capacitances of 125,550 , and $3000 \mathrm{pf}$.

3. Overvoltage gap breakdown voltage versus input voltage ramp rate for

five types of EG\&G gas-filled overvoltage gaps.

4. MC3858 waveforms obtained using a stored trigger energy of $2.7 \mathrm{~mJ}$ and a theoretical peak trigger voltage of $1344 \mathrm{~V}$.

5. MC3858 waveforms obtained using a stored trigger energy of $0.18 \mathrm{~mJ}$ and a peak trigger voltage of $402 \mathrm{~V}$.

6. MC3858 waveforms obtained using a stored trigger energy of $0.023 \mathrm{~mJ}$ and a peak trigger voltage of $49 \mathrm{~V}$.

7. MC3858 waveforms obtained for a sprytron with a trigger probe resistance of $10 \mathrm{Mohms}$. Trigger stored energy and initial peak trigger voltage are the same as in Figure 6.

8. 186 individual switch delay measurements made using two MC3858 sprytrons and 36 different trigger circuit configurations.

9. Average switch delays measured for each of 36 different trigger configurations using two MC3858 sprytrons.

10. Average switch delay versus peak trigger voltage (derived from the MC3858 data in Figure 9 using Table 1).

11. Average switch delay versus trigger stored energy (derived from the

MC3858 data in Figure 9 using Table 1).

12. Individual variations in switch delay versus average switch delay for the

MC3858 sprytron (derived from the individual and averaged switch delay measurements in Figures 8 and 9).

13. Variation in MC3858 switch delay versus peak trigger voltage (derived from the MC3858 data in Figure 8 using Table 1).

14. Variation in MC3858 switch delay versus trigger stored energy (derived from the MC3858 data in Figure 8 using Table 1).

15. Comparison of the switch delays for a MC3858 sprytron with a probe resistance varying up to 10 Mohms to the average switch delays of a normal MC3858. Symbols represent individual delays measured at high $R_{p}$. Solid lines bound the space containing the average delays measured at normal $R_{p}$ (from Figure 9). 


\section{FIGURES}

(continued)

16. Comparison of switch delays for a MC3858 sprytron operated at a bias of $725 \mathrm{~V}$ and a bias of $2420 \mathrm{~V}$. Symbols represent individual delays measured at $725 \mathrm{~V}$. Solid lines bound the space containing the average delays measured at $2420 \mathrm{~V}$. All measurements used the $1340 \mathrm{~V} / \mathrm{GP} 6555$ gap in the trigger circuit.

17. Comparison of switch delays for a MC3858 sprytron operated at a bias of $725 \mathrm{~V}$ and a bias of $2420 \mathrm{~V}$. Symbols represent individual delays measured at $725 \mathrm{~V}$. Solid lines bound the space containing the average delays measured at $2420 \mathrm{~V}$. All measurements used the $610 \mathrm{~V} / \mathrm{GP} 3955$ gap in the trigger circuit. 


\section{TABLES}

1. Stored trigger energy and peak trigger voltage for each of 36 trigger configurations. Each configuration is determined by the selection of triggering capacitance, filtering capacitance and overvoltage gap breakdown voltage. 


\section{INTRODUCTION}

Optimal design of fireset circuits, which make use of the current generation of sprytrons being produced for use in slapper and other detonation systems, requires detailed knowledge of the performance capabilities of the sprytron. In particular, it is very desirable to know the switch delay time of the sprytron under various use conditions so that the circuitry interfaced to the sprytron can be chosen to produce the desired switch delay times without placing high voltage requirements, stored energy requirements, trigger current risetime requirements, or other requirements on the circuit design which are unnecessary.

Some of the key circuit parameters which may directly influence the timing capabilities of the sprytron are: (1) the triggering capacitance, $C_{t}$, which provides stored energy for generating the sprytron trigger arc during switch turn-on, (2) the breakdown voltage, $V_{b}$, of the trigger circuit's overvoltage gap, which isolates the sprytron trigger from most of the trigger circuitry until trigger operation is desired, (3) the filtering capacitance, $C_{f}$, which is wired in parallel with the sprytron trigger and which provides immunity to noise triggering of the sprytron, (4) the resistance, $R_{p}$, of the sprytron trigger probe which varies over the shot-life of the sprytron and which may reach a very high resistance state after many firing operations of the sprytron, and (5) the bias voltage applied to the main gap of the sprytron when the capacitive discharge unit (CDU) of the detonator circuit is energized, and which may vary considerably for various applications.

Here, we have experimentally evaluated and formally documented how these five circuit parameters influence both the average switch delay time, and the shot-to-shot variability in the switch delay time, of the MC3858 sprytron. The rather detailed timing data presented here as a function of a number of key circuit parameters have not been available for any previous sprytron. This more complete evaluation of the timing capabilities of the MC 3858 sprytron is valuable from both a practical and a fundamental point of view. Hopefully, the engineer, who is interested in producing an efficient and reliable fireset, will come away from this work with a better appreciation of the circuit parameters which influence sprytron timing, and the scientist, who is investigating the device physics of sprytrons, will glean from this work useful fundamental data which may be used in the development of physical models of sprytrons. 


\section{EXPERIMENTAL DETAILS}

\subsection{Test Circuit and Test instrumentation}

The switch delay time of MC3858 sprytrons was evaluated using the test circuit shown in Figure 1. In order to investigate the effect of varying triggering capacitance, $C_{t}$, four values of $C_{t}$ were used in our test matrix. These were $125 \mathrm{pf}$ (SA2827-10), $330 \mathrm{pf}$ (SA2827-4), 1500 pf (SA2827-3), and 3000 pf (2 paralleled SA2827-3s). Similarly, three values of capacitance were used to investigate the effect of varying filter capacitance, $C_{f}$. These were 0 pf, $550 \mathrm{pf}$ (SA2827-9), and $1500 \mathrm{pf}$ (SA2827-3). Three nominal values of overvoltage gap breakdown voltage, $V_{b}$, were used to investigate the effect of varying gap breakdown voltage. These were $610 \mathrm{~V}$ (GP3955), $1030 \mathrm{~V}$ (GP9411), and $1340 \mathrm{~V}$ (GP6555). These breakdown voltages correspond to a voltage ramp rate at the gap input of $\sim 4-7 \mathrm{~V} / \mathrm{ns}$. The complete triggering study is a $4 \times 3 \times 3$ test matrix with 36 separate trigger configurations.

As shown in Figure 1, the test circuit was heavily instrumented so that a variety of test waveforms could be collected on each shot. Sprytron current and voltage waveforms, overvoltage gap input and output voltage waveforms, trigger current waveforms, and FET gate voltage waveforms were measured for all shots. Overvoltage gap voltages and sprytron voltages were measured with 100:1, $120 \mathrm{MHz}, 100 \mathrm{M} \Omega$ scope probes (Tektronics, Model P6009) referenced to the cathode of the sprytron. The FET gate voltage was measured with a 10:1, $400 \mathrm{MHZ}, 10 \mathrm{M} \Omega$ scope probe (Tektronics, Model P6137) referenced to ground. Sprytron current was measured using a low inductance, $250 \mathrm{~m} \Omega$ load, incorporating a $10 \mathrm{~m} \Omega$ current viewing resistor (CVR, T\&M Research Products, Model SDN-250-01-TT). Finally, trigger current was measured with a $1 \mathrm{~V} / \mathrm{A}, 70 \mathrm{MHz}, 50 \mathrm{\Omega}$ current viewing transformer (CVT, Pearson Electronics, Model 2877).

Three Tektronix 2440 digital oscilloscopes and a Tektronix DSA 602 Digitizing Signal Analyzer were used to acquire the waveform data, and a HP $8116 \mathrm{~A}$ pulse generator was used to initiate each test shot. These instruments were interfaced to a HP Vectra QS/20 personal computer using a National Instruments IEEE-488 interface card.

It is worth noting that insertion of the CVT into the trigger circuit to monitor the trigger current added extra inductance to the trigger circuit discharge loop. The inductance of the present trigger circuit appears to be $\sim 60 \mathrm{nH}$ based on both analysis of the trigger circuit current ringdown, and direct measurement of the discharge loop inductance with the overvoltage gaps and capacitors shorted. Sprygaps typically have the trigger capacitor, overvoltage gap, and filter capacitor mounted directly on the sprytron trigger leads, and a trigger discharge loop inductance of $\sim 30 \mathrm{nH}$ or less should be obtainable. The extra $\sim 30$ $\mathrm{nH}$ of inductance present in our circuit reduces the peak trigger current by as much as 30 percent, and increases the trigger current pulse width by as much as 40 percent.

\subsection{Technique Used to Determine Switch Delay Time}

A variety of tube performance parameters were determined for each shot. Most important among these for this study was the switch delay time. Here, the switch delay time is defined by:.

$$
\mathrm{T}_{\mathrm{ad}}=\mathrm{T}_{2}-\mathrm{T}_{1}
$$




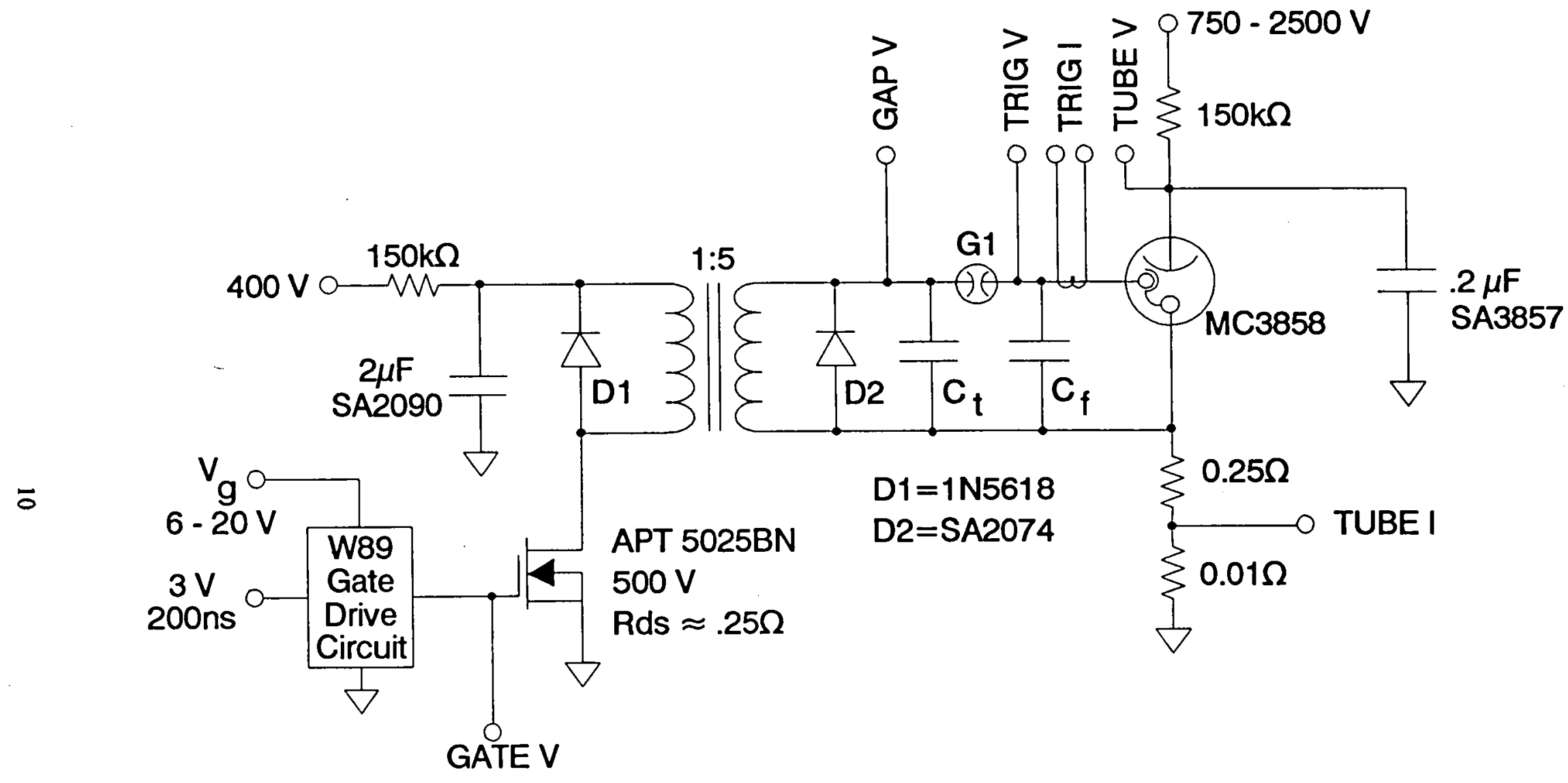

Figure 1. Test circuit used to study factors affecting switch tube timing. 
where: $\quad T_{2}=$ the point in time where the sprytron trigger voltage (gap output voltage) begins to rise due breakdown of the overvoltage gap, and

$T_{1}=$ the point in time where the sprytron begins to significantly conduct current.

$\mathrm{T}_{2}$ was determined numerically from the recorded gap output voltage waveform by locally calculating the waveform slope, $d V / d t$. The time where $d V / d t$ was found to first exceed a threshold value of $10 \mathrm{~V} / \mathrm{ns}$ was defined to be $T_{2}$. In order to define $T_{1}$ precisely, we determined the points where sprytron current reached 10 percent of maximum and 30 percent of maximum and used these points to linearly extrapolate the current waveform backwards in time to zero current. The time corresponding to zero extrapolated current was defined to be $T_{1}$.

Noise in the measured waveforms, combined with the simplistic methods used here to determine $T_{1}$ and $T_{2}$, introduce a component of variability in $T_{a d}$ which is solely due to the measurement technique. For example, use of the slope approach in determining $T_{2}$ generally agreed with results obtained by visually inspecting the overvoltage gap output waveform to within 2 nsec. Similarly, a crosscheck on the variability of $T_{1}$, due to the two-point extrapolation approach used for determining $T_{1}$, was made. We made an alternative calculation of $T_{1}$ using the 30 percent of maximum current and the 50 percent of maximum current points to do the extrapolation. Comparison of the two results suggests that the variability of $T_{1}$ due to noise in the sprytron current waveform is approximately $\pm 3 \mathrm{nsec}$. Below we will report maximum switch delay time variations which approach a minimum value of 6 nsec. Based on the above discussion, a significant component of these smallest measured variations are due to the waveform analysis technique and waveform noise.

\subsection{Ramp Rate Capability of Test Circuit vs. Triggering Capacitance}

Prior to performing our trigger matrix study of the MC3858, the capability of our test circuit to produce desired voltage ramp rates at the trigger capacitor was characterized. In these experiments we controlled the trigger capacitor voltage ramp rate by adjusting the FET gate voltage between $6 \mathrm{~V}$ and $20 \mathrm{~V}$. Typical ramp rates obtained for various values of trigger capacitance of interest are shown in Figures 2 . The ramp rates in Figure 2 correspond to the slope of the gap input voltage waveform between $\left(V_{b}-50 \mathrm{~V}\right)$ and $\left(\mathrm{V}_{\mathrm{b}}\right.$ $250 \mathrm{~V}$ ) (i.e., only the last $\sim 200 \mathrm{~V}$ of the ramp was used to estimate the ramp rate, and the ramp rate was measured with the gap in place). The different symbol types shown in Figure 2 correspond to the use of overvoltage gaps with different $V_{b}$. The lack of agreement between data taken with different gap breakdown voltages reflects the fact that the voltage ramp produced at $C_{t}$ by the circuit in Figure 1 is not a perfectly linear ramp. In this work we wanted to maintain the ramp rate constant at about $4-7 \mathrm{~V} / \mathrm{ns}$ for different values of triggering capacitance. This was done by using an appropriate value of FET gate bias for each trigger capacitance used.

\subsection{Overvoltage Gap Breakdown Voltage vs. Ramp Rate}

The dependence of overvoltage gap breakdown voltage on ramp rate was also evaluated prior to performing our trigger matrix study. Several types of gaps designed for use with 


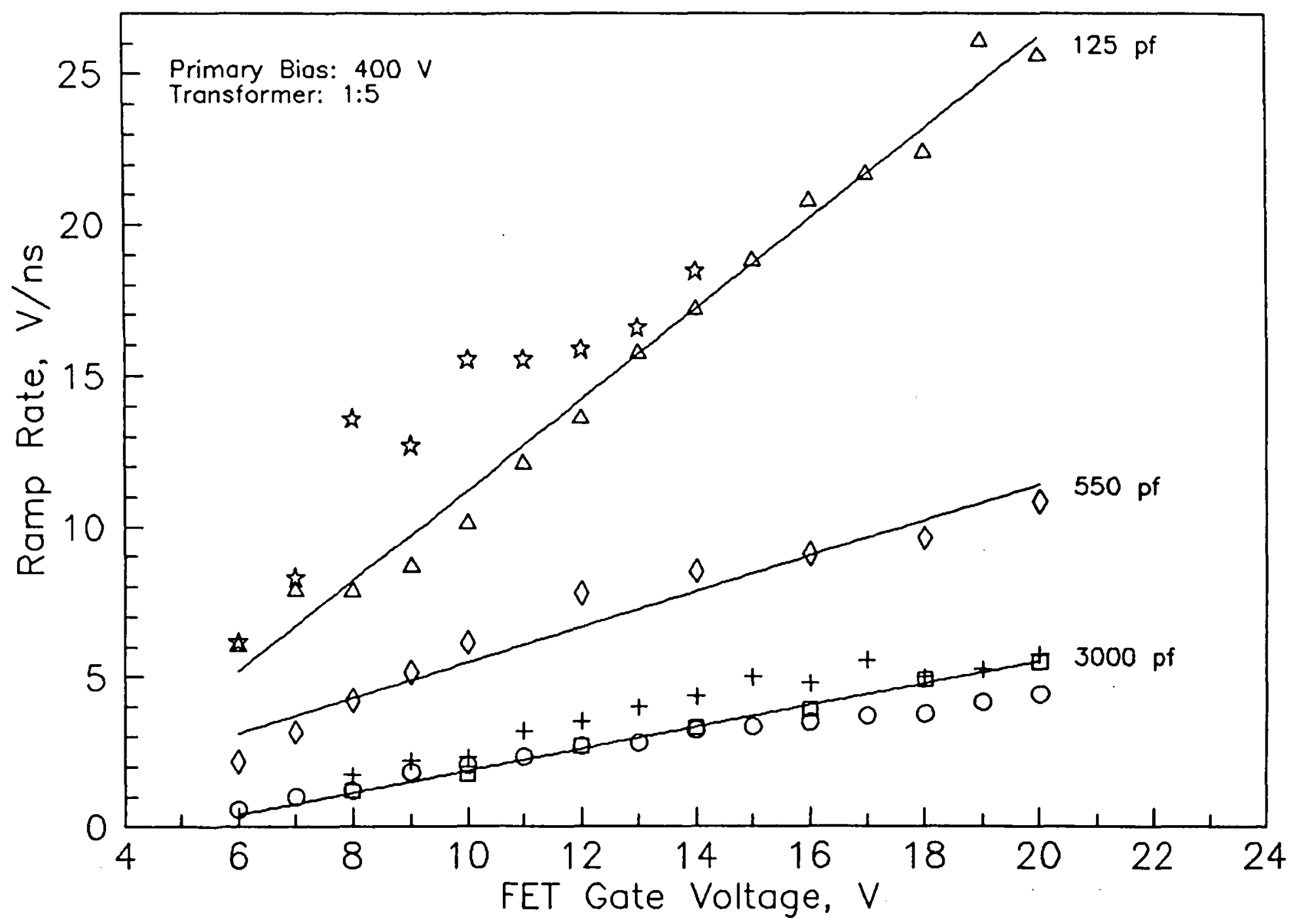

Figure 2.

Trigger capacitor voltoge ramp rate versus trigger circuit FET gate voltage for trigger copocitances of 125,550 and 3000 pf. 
sprytrons were readily available: GP3955, GP3860, GP9411, GP4064, and GP6555. We evaluated their breakdown voltage as a function of ramp rate. The results of this evaluation are shown in Figure 3. The ramp rates in Figure 3 were determined as described above for Figure 2. Since the GP3955, GP9411, and GP6555 appear representative of the low, medium, and high gap breakdown voltages typically used with sprytrons, these gaps were selected for use in our study. 


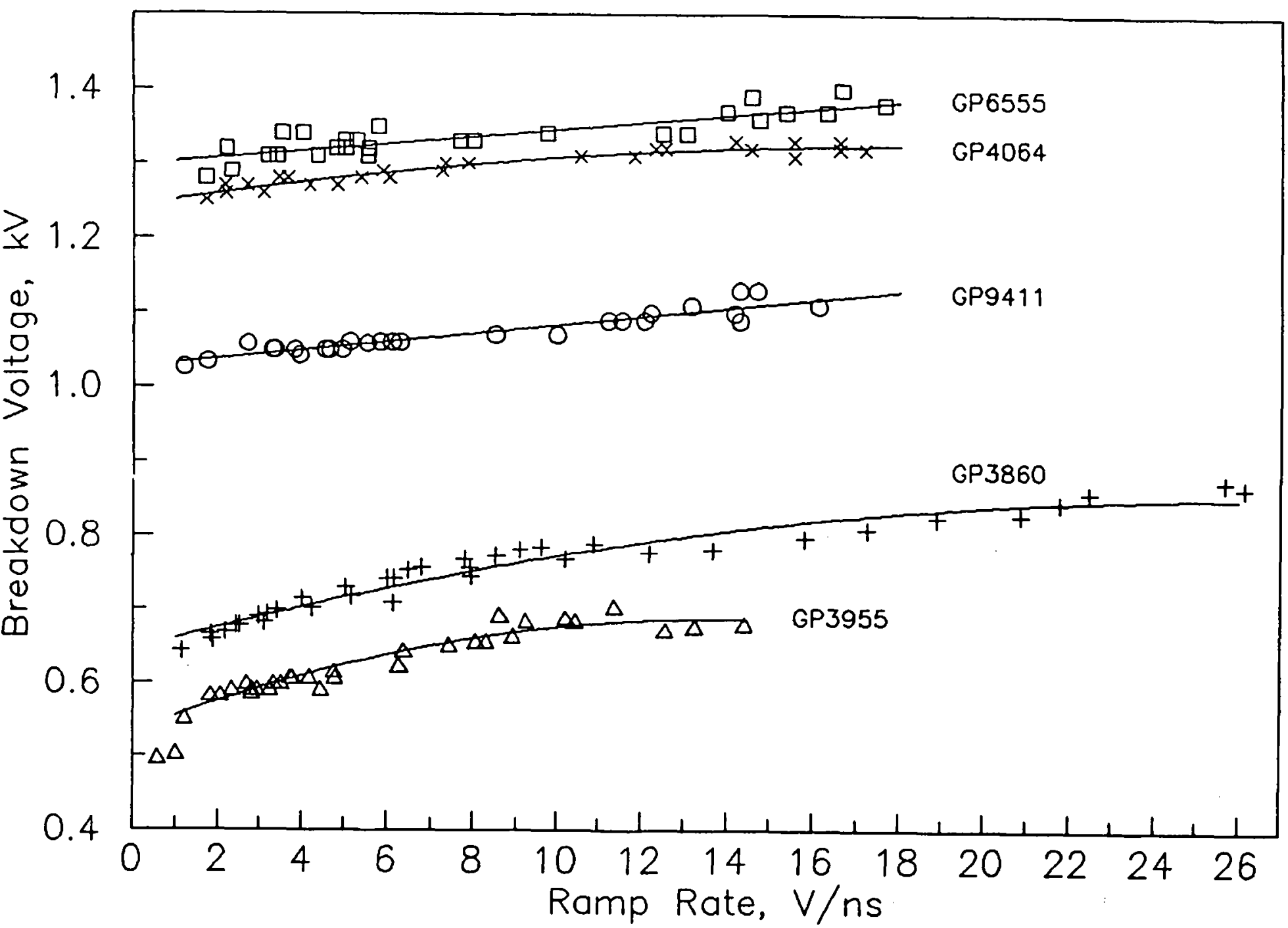

Figure 3 .

Overvoltage gap breakdown voltoge versus input voltoge romp rate for five types of EG\&G gas-filled overvoltage gops. 


\section{TYPICAL WAVEFORMS}

Taken together, the triggering capacitance, the overvoltage gap breakdown voltage, and the filtering capacitance determine the peak voltage that can be applied to the sprytron trigger. The peak trigger voltage, $V_{t}$, is given by the equation:

$$
V_{t}=V_{b}\left[C_{t} /\left(C_{t}+C_{f}\right)\right]
$$

The triggering capacitance and the overvoltage gap breakdown voltage determine the stored energy available to the sprytron trigger. The stored trigger energy is given by:

$$
E_{t}=1 / 2\left[C_{t}\left(V_{b}\right)^{2}\right]
$$

The three dimensional test matrix outlined above, which consists of variations in three key trigger circuit elements, can be mapped into a two dimensional space consisting of peak trigger voltages and stored trigger energies using Eqs. (2) and (3). The trigger voltages and energies corresponding to our test matrix are shown in Table 1. We used trigger energies ranging from $0.023 \mathrm{~mJ}$ to $2.69 \mathrm{~mJ}$, and we used peak trigger voltages ranging from $47 \mathrm{~V}$ to $1340 \mathrm{~V}$.

Waveforms showing typical MC3858 sprytron performance at high trigger energy and voltage, medium trigger energy and voltage, and low trigger energy and voltage are shown in Figures 4-6, respectively. Figure 7 shows typical performance waveforms for an aged sprytron with a very high resistance trigger operated at low trigger energy and voltage.

\subsection{Typical Waveforms for High Trigger Energy and Voltage}

The overvoltage gap input and output voltage waveforms, and trigger current waveforms in Figure 4 illustrate the trigger performance for a MC3858 sprytron operated at a theoretical peak trigger voltage of $1344 \mathrm{~V}$ (from Eq. (2)) and stored trigger energy of $2.7 \mathrm{~mJ}$ (from Eq. (3)). In Figure 4, there is a $\sim 300 \mathrm{~V}$ drop across the overvoltage gap during the first 30 nsec following gap breakdown, and the actual voltage applied to the trigger is less than that implied by Eq. (2) above. The voltage drop across the overvoltage gap limits the actual peak voltage applied to the trigger to $\sim 1000 \mathrm{~V}$, and the theoretical value of $1344 \mathrm{~V}$ labeled in Figure 4 is never reached. As will be seen in Figures 5-7 below, the gap input and output voltage become equal much more quickly when a nonzero filter capacitance is used, and in contrast to the present case, the observed initial trigger voltage tends to oscillate about a voltage given by Eq. (2).

The delay between the application of voltage to the trigger and the observation of a trigger current greater than $\sim 3 \mathrm{~A}$ is approximately $5 \mathrm{nsec}$. The maximum ohmic current flow in the trigger is $\sim 3 \mathrm{~A}$ at $1000 \mathrm{~V}$. Thus, the rapid rise in trigger current to well past $3 \mathrm{~A}$ immediately following the application of trigger voltage indicates that the processes which lead to initiation of the trigger vacuum arc take on the order of only 5 nsec.

Examining the trigger waveforms, we see that the trigger circuit is underdamped once the trigger circuit vacuum arc develops. Analysis of the ringdown suggests an equivalent resistance for the trigger circuit of approximately $2 \Omega$. The trigger current rings down in 
Table 1. Stored trigger energy and peak trigger voltage for each of 36 trigger configurations. Each configuration is determined by the selection of triggering capacitance, filtering capacitance and overvoltage gap breakdown voltage.

\begin{tabular}{|c|c|c|c|c|c|c|c|c|c|}
\hline \multirow{3}{*}{$\begin{array}{l}\mathrm{C}_{t} \\
\text { (pf) }\end{array}$} & \multicolumn{3}{|c|}{$\begin{array}{c}\text { GP } 6555 \\
1340 \mathrm{~V}\end{array}$} & \multicolumn{3}{|c|}{$\begin{array}{c}\text { GP } 9411 \\
1030 \mathrm{~V}\end{array}$} & \multicolumn{3}{|c|}{$\begin{array}{c}\text { GP } 3955 \\
610 \mathrm{~V}\end{array}$} \\
\hline & & & & & $f(p F)$ & & & & \\
\hline & 0 & 550 & 1500 & 0 & 550 & 1500 & 0 & 550 & 1500 \\
\hline 125 & $\begin{array}{c}0.112 \mathrm{~mJ} \\
1340 \mathrm{~V}\end{array}$ & 248 & 103 & $\begin{array}{c}0.0663 \mathrm{~mJ} \\
1030 \mathrm{~V}\end{array}$ & 191 & 79 & $\begin{array}{l}0.0231 \mathrm{~mJ} \\
610 \mathrm{~V}\end{array}$ & 113 & 47 \\
\hline 330 & $\begin{array}{c}0.296 \mathrm{~mJ} \\
1340\end{array}$ & 503 & 242 & $\begin{array}{c}0.175 \mathrm{~mJ} \\
1030\end{array}$ & 386 & 186 & $\begin{array}{c}0.0610 \mathrm{~mJ} \\
610\end{array}$ & 229 & 110 \\
\hline 1500 & $\begin{array}{c}1.35 \mathrm{~mJ} \\
1340\end{array}$ & 980 & 670 & $\begin{array}{c}0.796 \mathrm{~mJ} \\
1030\end{array}$ & 754 & 515 & $\begin{array}{c}0.277 \mathrm{~mJ} \\
610\end{array}$ & 446 & 305 \\
\hline 3000 & $\begin{array}{c}2.69 \mathrm{~mJ} \\
1340\end{array}$ & 1132 & 893 & $\begin{array}{c}1.59 \mathrm{~mJ} \\
1030\end{array}$ & 870 & 687 & $\begin{array}{c}0.55 \mathrm{~mJ} \\
610\end{array}$ & 515 & 407 \\
\hline
\end{tabular}




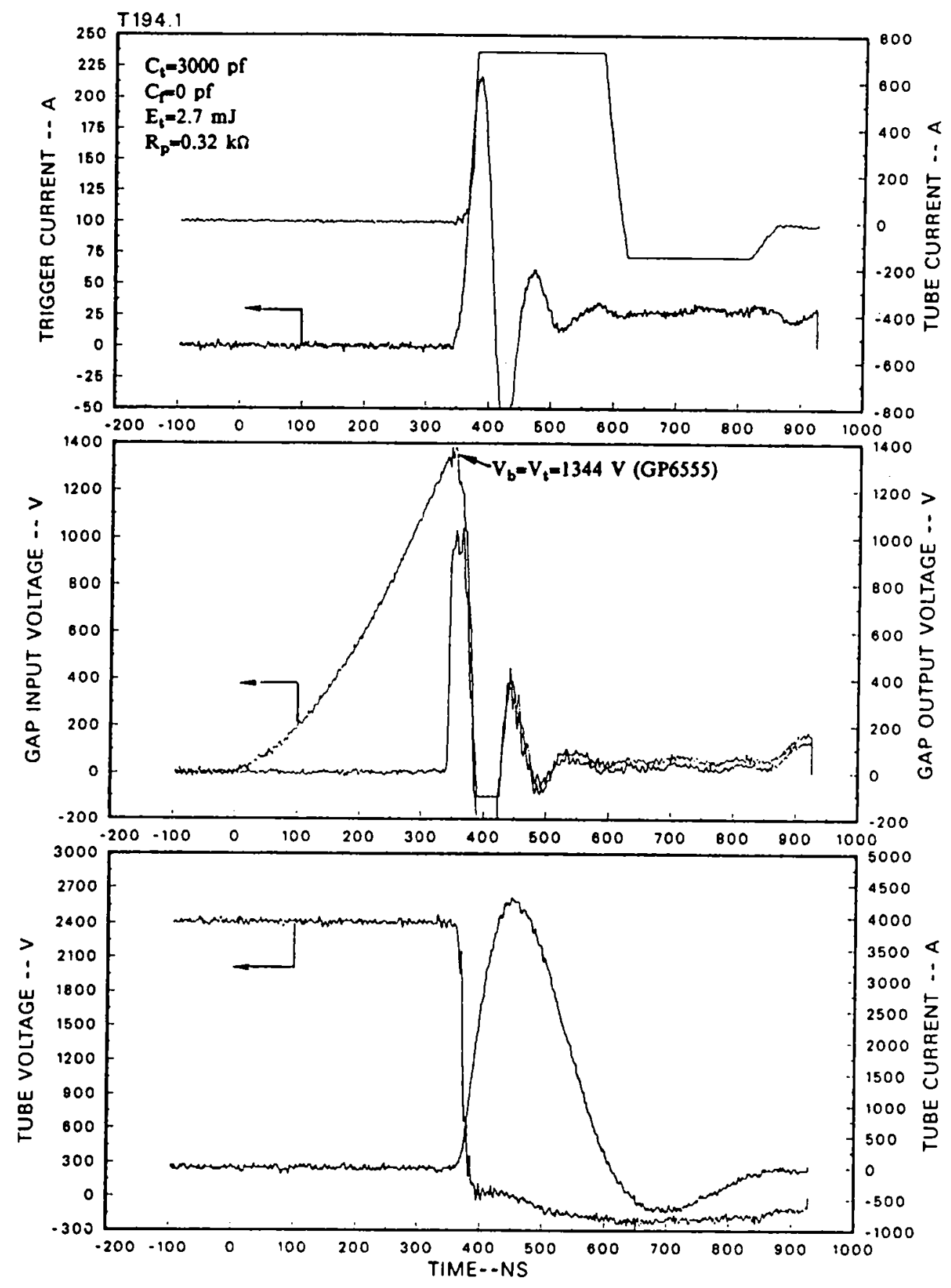

Figure 4. MC3858 waveforms obtained using a stored trigger energy of $2.7 \mathrm{~mJ}$ and a theoretical peak trigger voltage of $1344 \mathrm{~V}$. 

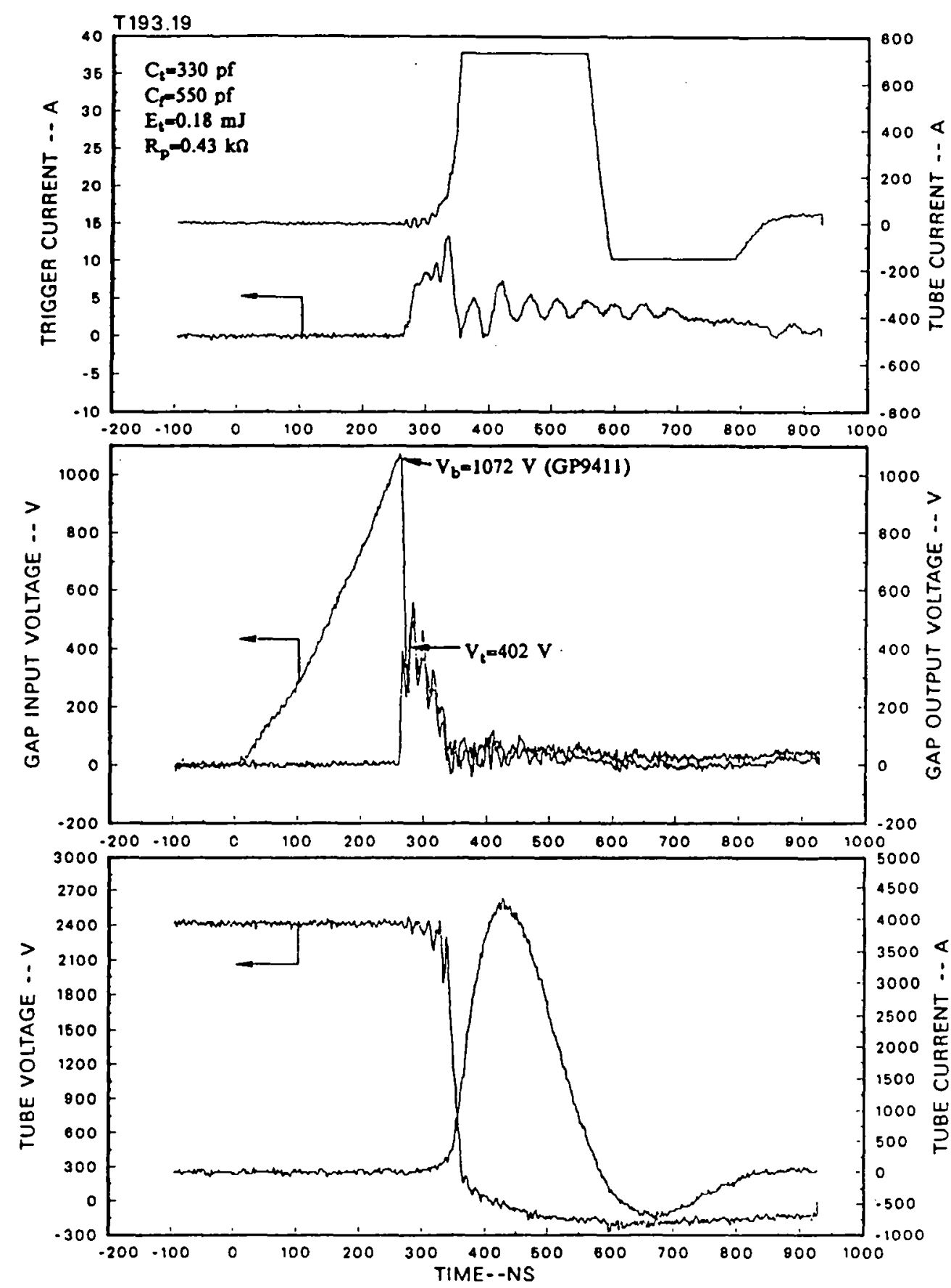

Figure 5. MC3858 waveforms obtained using a stored trigger energy of $0.18 \mathrm{~mJ}$ and a peak trlgger voltage of $402 \mathrm{~V}$. 


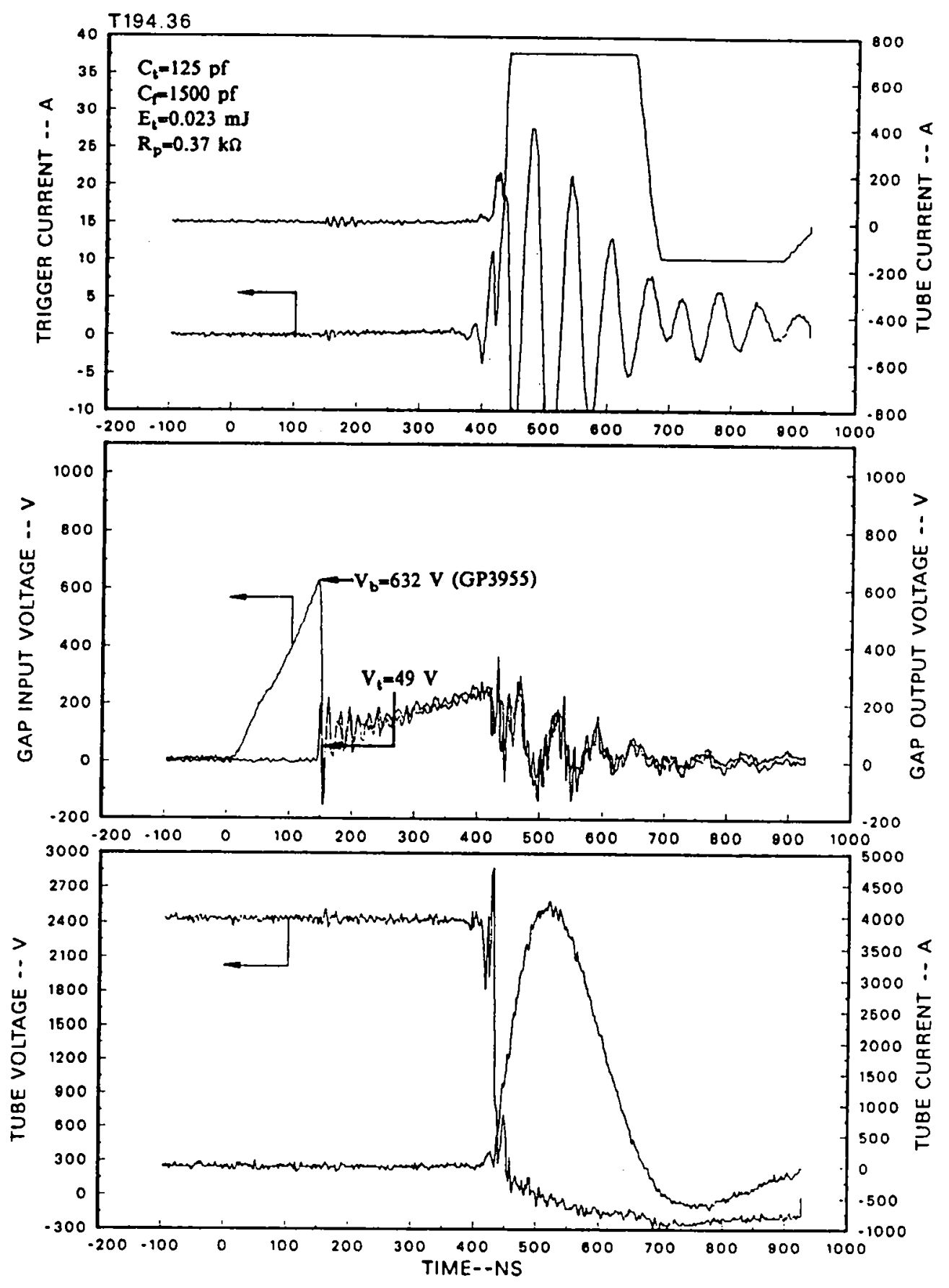

Figure 6. MC3858 waveforms obtained using a stored trigger energy of $0.023 \mathrm{~mJ}$ and a peak trigger voltage of $49 \mathrm{~V}$. 

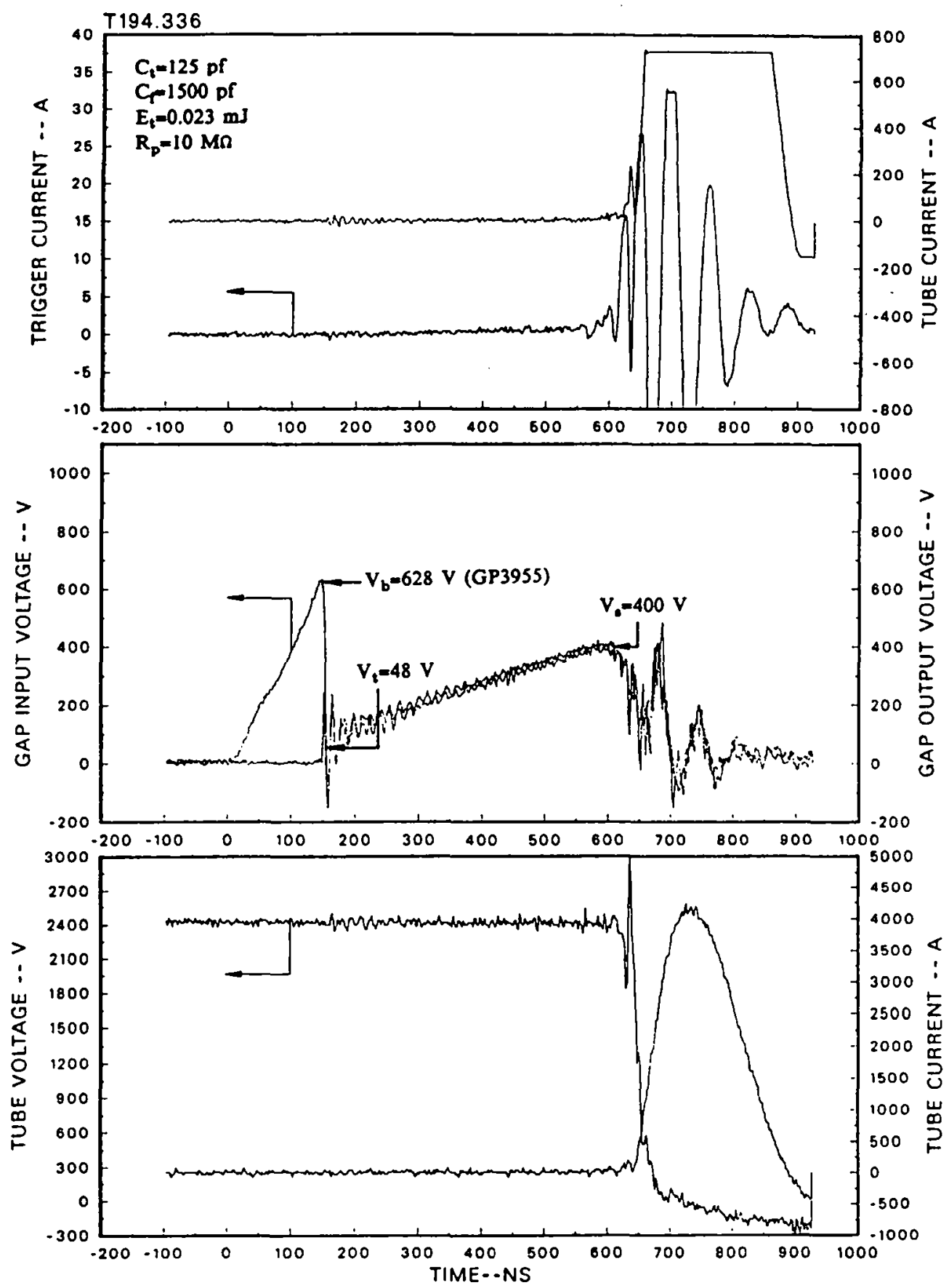

Figure 7. MC3858 waveforms obtained for a sprytron with a trigger probe resistance of 10 Mohms. Trigger stored energy and initial peak trigger voltage are the same as in Figure 6. 
about 250 nsec to a steady current of 25 A resulting from the current flowing in the trigger circuit primary. In Figure 4, the onset of rapid tube voltage collapse and rapid rise in switch current occurs well before the trigger current rises to its maximum value of $217 \mathrm{~A}$. The onset of tube conduction occurs 20 nsec after trigger current begins to flow, and the trigger current at this time has only reached $100 \mathrm{~A}$.

\subsection{Typical Waveforms for Medium Trigger Energy and Voltage}

Figure 5 shows the MC3858 waveforms which result if the peak trigger voltage is reduced to $402 \mathrm{~V}$ and the stored trigger energy is reduced to $0.18 \mathrm{~mJ}$. In contrast to the trigger configuration used to obtain the data shown in Figure 4, the trigger configuration used here has similar triggering and filtering capacitances. The filter capacitor attenuates the overvoltage gap breakdown voltage by distributing the initial charge on the trigger capacitor between $C_{t}$ and $C_{t}$ connected in parallel once the overvoltage gap breaks down. The resulting peak trigger voltage is given in Eq. (2) above. In Figure 5, we see that the gap output rises immediately upon gap breakdown to the nominal value of $402 \mathrm{~V}$ predicted by Eq. (2). In contrast to Figure 4, in Figure 5 the initial voltage drop that develops across the overvoltage gap vanishes within 10-15 nsec, rather than 30 nsec.

The trigger current waveform in Figure 5 is substantially different from that obtained in Figure 4. The trigger current rises rapidly following the application of trigger voltage (within $5 \mathrm{nsec}$ as before). However, the trigger circuit does not immediately enter an underdamped ringdown mode as in Figure 4. In the underdamped condition the trigger ideally would oscillate with a period of $46 \mathrm{nsec}$ and would have an initial peak current approaching $60 \mathrm{~A}$. Here, the trigger current initially exhibits an overdamped character with no 46 nsec oscillations. The 16 nsec period oscillations initially observed after gap breakdown on the trigger current and gap voltage waveforms appear more consistent with the natural frequency of the smaller, lower inductance, $C_{t}--g a p--C_{f} l o o p$, rather than the full trigger loop.

Assuming an initially overdamped trigger circuit where the equivalent resistance of the trigger probe arc dominates trigger current, we can estimate the nominal equivalent resistance of the trigger using the trigger current and voltage. This approach suggests that the trigger resistance appears to drop from near $57 \Omega$ at trigger arc initiation to as low as 14 $\Omega$ just prior to the rapid increase in tube conduction. This result is consistent with the critical damping resistance of the trigger circuit of $16 \Omega$.

Once the tube conducts, the equivalent trigger resistance is small and the trigger circuit becomes underdamped. Note in Figure 5 that at the point in time where the tube current begins to rise rapidly, the trigger begins to oscillate with the expected 46 nsec natural period of the trigger loop. The trigger current eventually oscillates about a 7 A level corresponding to current flow in the trigger circuit primary. This current level is lower than the $25 \mathrm{~A}$ level observed in Figure 4 because the FET gate voltage has been changed in order to maintain the same voltage ramp rate at the terminals of $C_{t}$ for all trigger circuit configurations. 


\subsection{Typical Waveforms for Low Trigger Energy and Voltage}

Figure 6 shows MC3858 waveforms acquired at the lowest peak trigger voltage $(49 \mathrm{~V})$ and lowest stored trigger energy $(0.023 \mathrm{~mJ})$ considered in this study. In this case, the trigger does not immediately strike an arc after the application of voltage to the sprytron trigger. Instead, the trigger conducts a very low current of a few tenths of an ampere for approximately $275 \mathrm{~ns}$. The low current is consistent with the average voltage applied to the trigger $(\sim 150 \mathrm{~V})$ and the resistance of the trigger probe $(370 \Omega)$. During this $275 \mathrm{~ns}$, the sprytron trigger undergoes a linear voltage ramp as the trigger circuit charges up $C_{t}$ and $C_{f}$, which are now connected in parallel by the shorted overvoltage gap. The trigger ultimately undergoes high voltage breakdown at about $250 \mathrm{~V}$.

When the trigger voltage is very low as in this case, the switch delay is dominated by the processes which lead to high voltage breakdown of the trigger. In contrast, the switch delay for the cases shown in Figure 4 and 5 are dominated by the processes which govern development of the trigger arc once trigger breakdown has been initiated.

The final example waveform data shown in Figure 7 are for the case of a sprytron with a high resistance trigger probe. The performance is very similar to that observed in Figure 6. A major difference is that $V_{8}$, the voltage required to break down the secondary gap formed by the high resistance trigger ( $400 \mathrm{~V}$ in Figure 7 ), is significantly larger than the voltage normally reached by the trigger when the trigger resistance is low (250 V in Figure 6). 


\section{AVERAGE SWITCH DELAY TIME}

Switch delay times typical of new MC3858 sprytrons (as received following factory testing at EG\&G) were determined by operating two MC3858 sprytrons (MC3858-18-8942-193 and MC3858-18-8942-194) using the 36 trigger configurations described above. Tube 193 was tested for 1 full trigger matrix (nominally 36 shots). This tube had a probe resistance of 690 $\Omega$ as received, and a probe resistance of $420 \Omega$ after the completion of 1 trigger matrix. Tube 194 was tested for four full trigger matrices (nominally 144 shots). This tube had a probe resistance of $320 \Omega$ as received, and a probe resistance of $350 \Omega$ after 144 shots. The individually measured switch delay results for all these test shots are shown in Figure 8 as a function of trigger capacitance. Averaging the delay measurements for each trigger configuration produces the data shown in Figure 9.

\subsection{Average Switch Delay vs Peak Trigger Voltage}

In order to systematically examine the average delay time data shown in Figure 9, we used the trigger voltage and stored energy data in Table 1 for $C_{t}, C_{f}$ and $V_{b}$, to recast the data as a function of peak trigger voltage, $V_{t}$, and trigger stored energy, $E_{t}$. Examining Table 1 , we see that there are groups of trigger configurations which have approximately the same stored energy. For example, the three configurations at $1.35 \mathrm{~mJ}$ and the three configurations at $1.59 \mathrm{~mJ}$ can be collected together to form a more useful, larger size group with an average stored energy of $1.5 \mathrm{~mJ}$. We formed seven such constant energy groups from our 36 configurations. This allowed us to more clearly plot average switch delay vs peak trigger voltage while holding trigger energy approximately constant. The resulting seven iso- $\mathrm{E}_{\mathrm{t}}$ curves are shown in Figure 10.

In Figure 10 we see that the average delay time is a very strong function of $V_{t}$ at relatively low voltages. As $V_{t}$ increases, the decrease in average switch delay begins to saturate. Around $800 \mathrm{~V}$, the decrease in switch delay time with increasing $V_{t}$ is nearly complete, and increasing $\mathrm{V}_{\mathrm{t}}$ beyond $800 \mathrm{~V}$ leads to very modest decreases in average switch delay. A final interesting feature of Figure 10 is that the $2.7 \mathrm{~mJ}, 1.5 \mathrm{~mJ}$ and $0.67 \mathrm{~mJ}$ iso- $E_{t}$ curves merge to form a single curve. This indicates that increasing $E_{t}$ above $0.67 \mathrm{~mJ}$ will not significantly decrease average switch delay time.

\subsection{Average Switch Delay vs Trigger Stored Energy}

The effect of increasing trigger stored energy can be more clearly illustrated by regrouping the average delay time data into groups of approximately constant trigger voltage, and then plotting the data as a function $\mathrm{E}_{\mathrm{t}}$. Again we used the data in Table 1, and we formed six groups of trigger configurations which had approximately constant peak trigger voltages, $V_{t}$. The resulting six iso- $V_{t}$ curves are plotted in Figure 11 .

In Figure 11 we see that the average switch delay time is highly dependent on $E_{t}$ when $E_{t}$ is low. As $E_{t}$ is increased and approaches $0.5 \mathrm{~mJ}$, the decrease in average switch delay time saturates. Increasing $E_{t}$ beyond $0.5 \mathrm{~mJ}$ leads to little, if any, decrease in average switch delay time. 


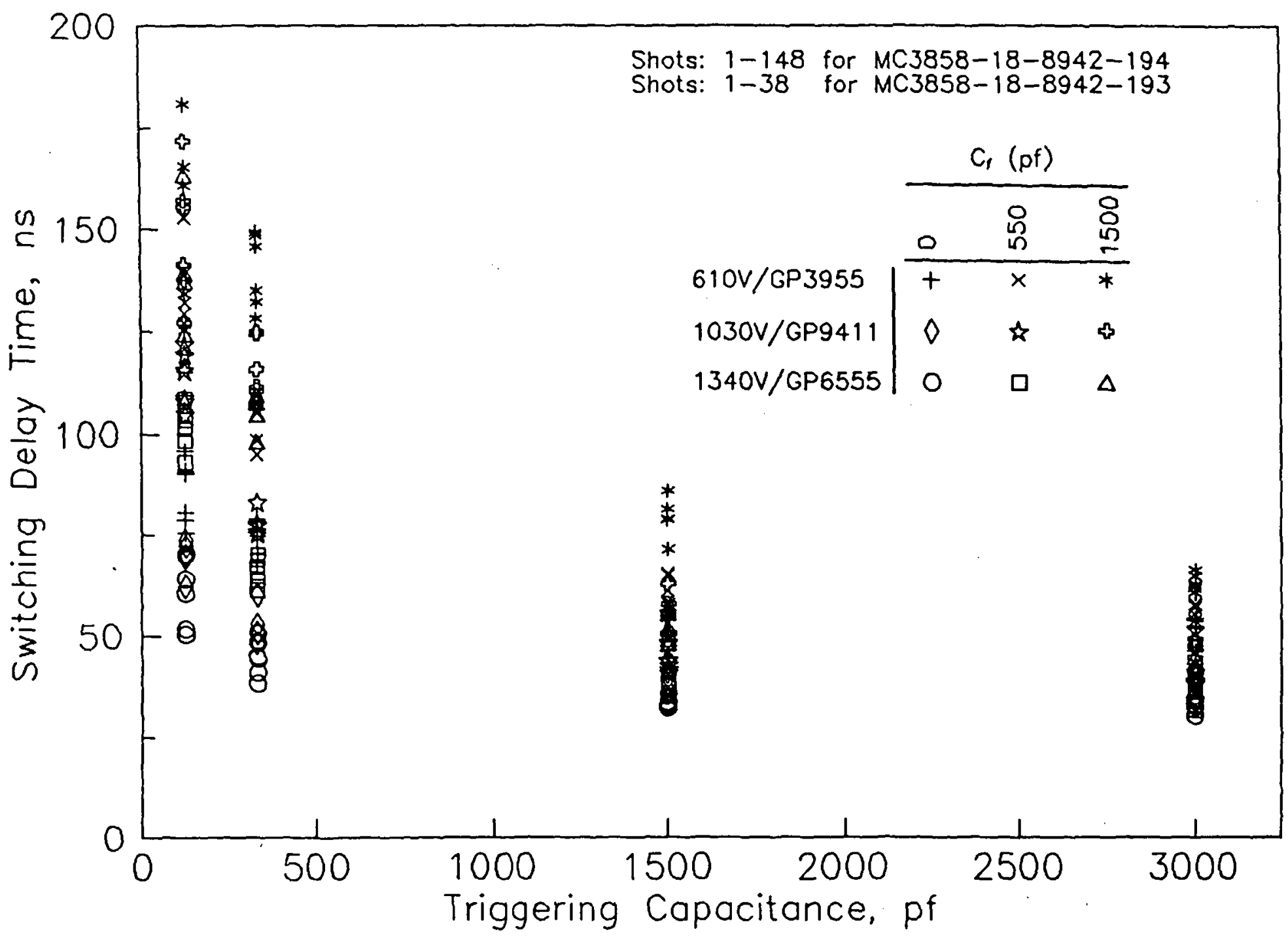

Figure 8.

186 individual switch delay measurements mode using two MC3858 sprytrons and 36 different trigger circuit configurations. 


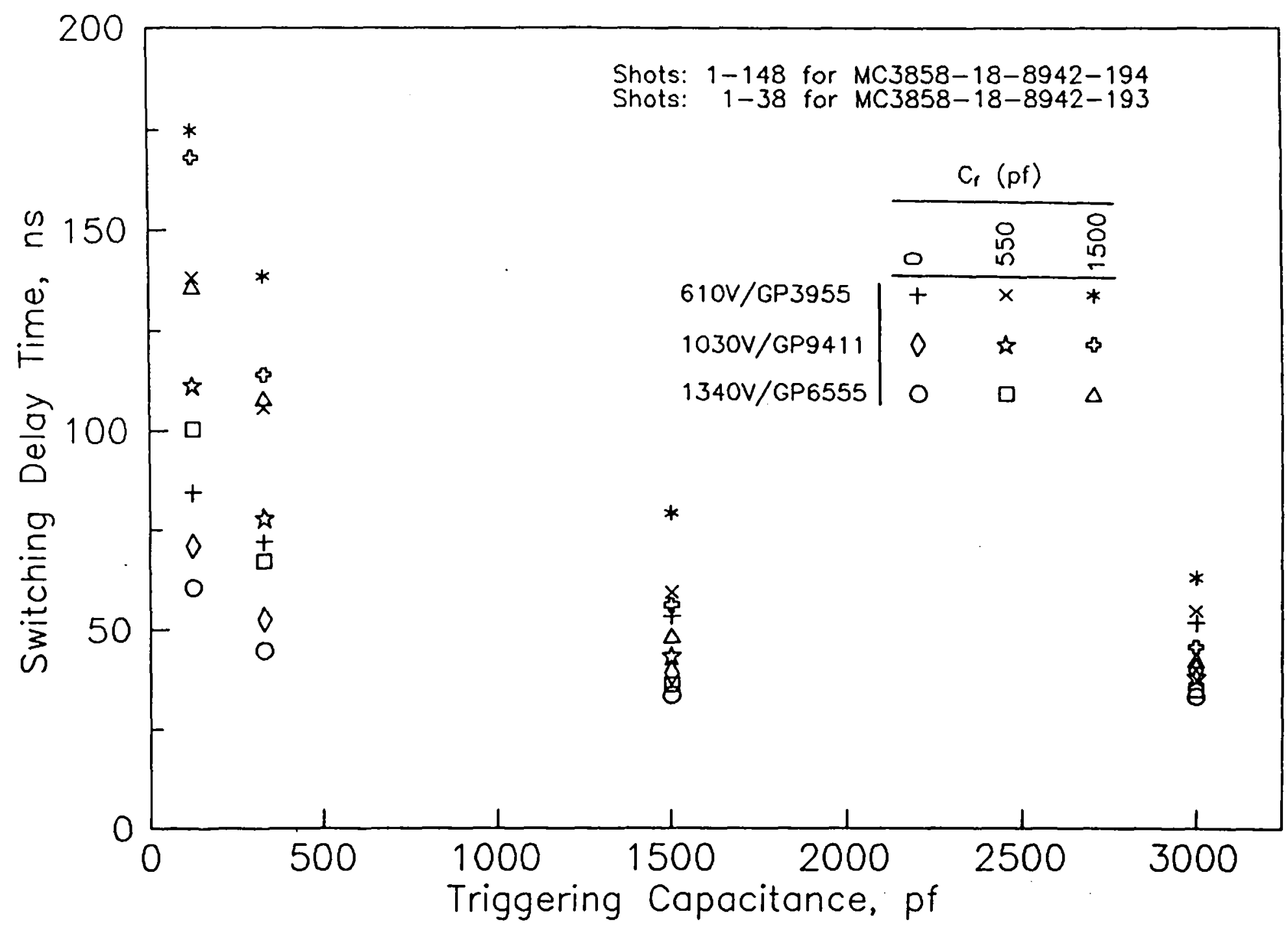

Figure 9.

Average switch deloys meosured for each of 36 different trigger configurations using two MC3858 sprytrons. 


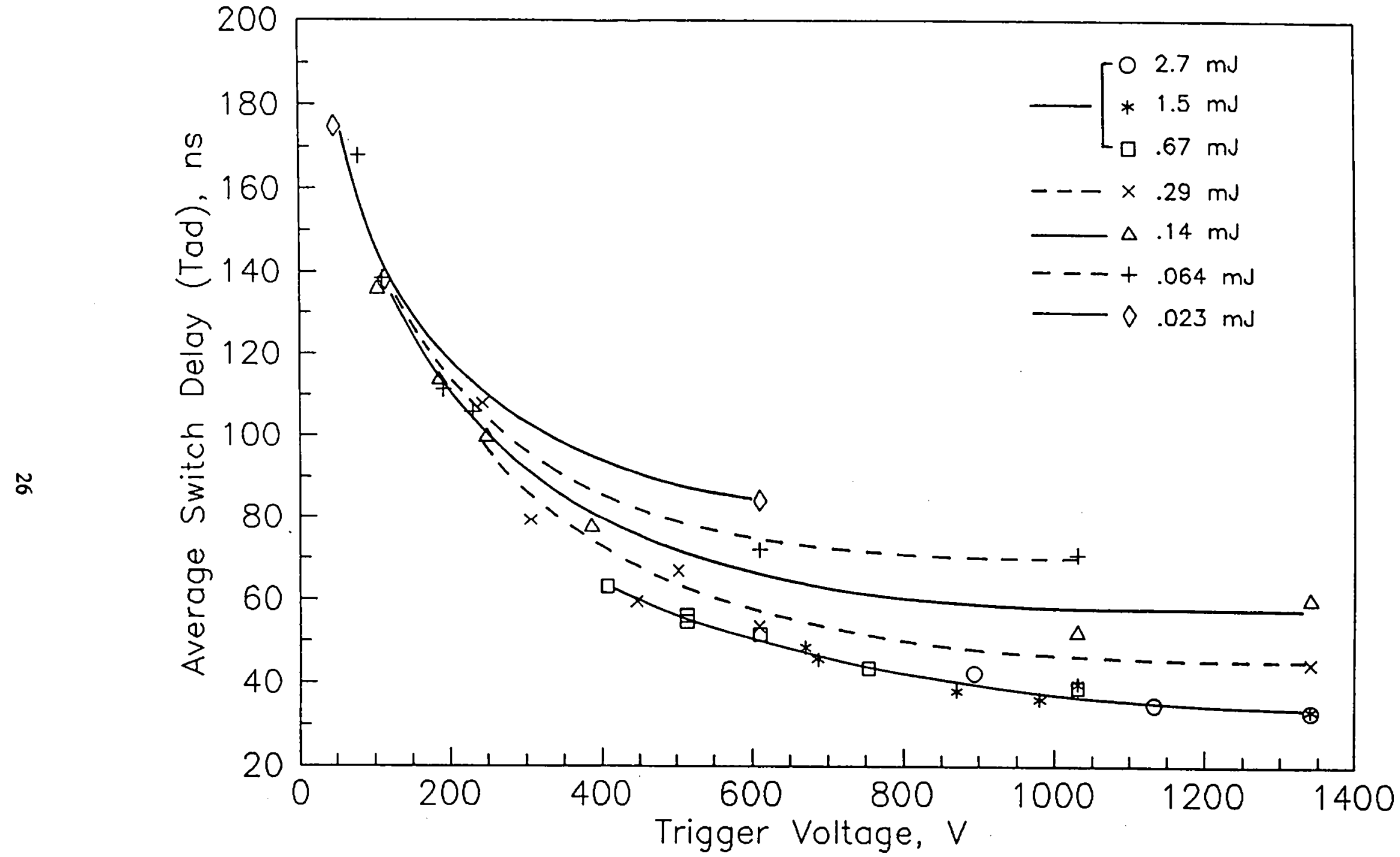

Figure 10.

Averoge switch deloy versus peak trigger voltoge (derived from the MC3858 dato in Figure 9 using Table 1). 


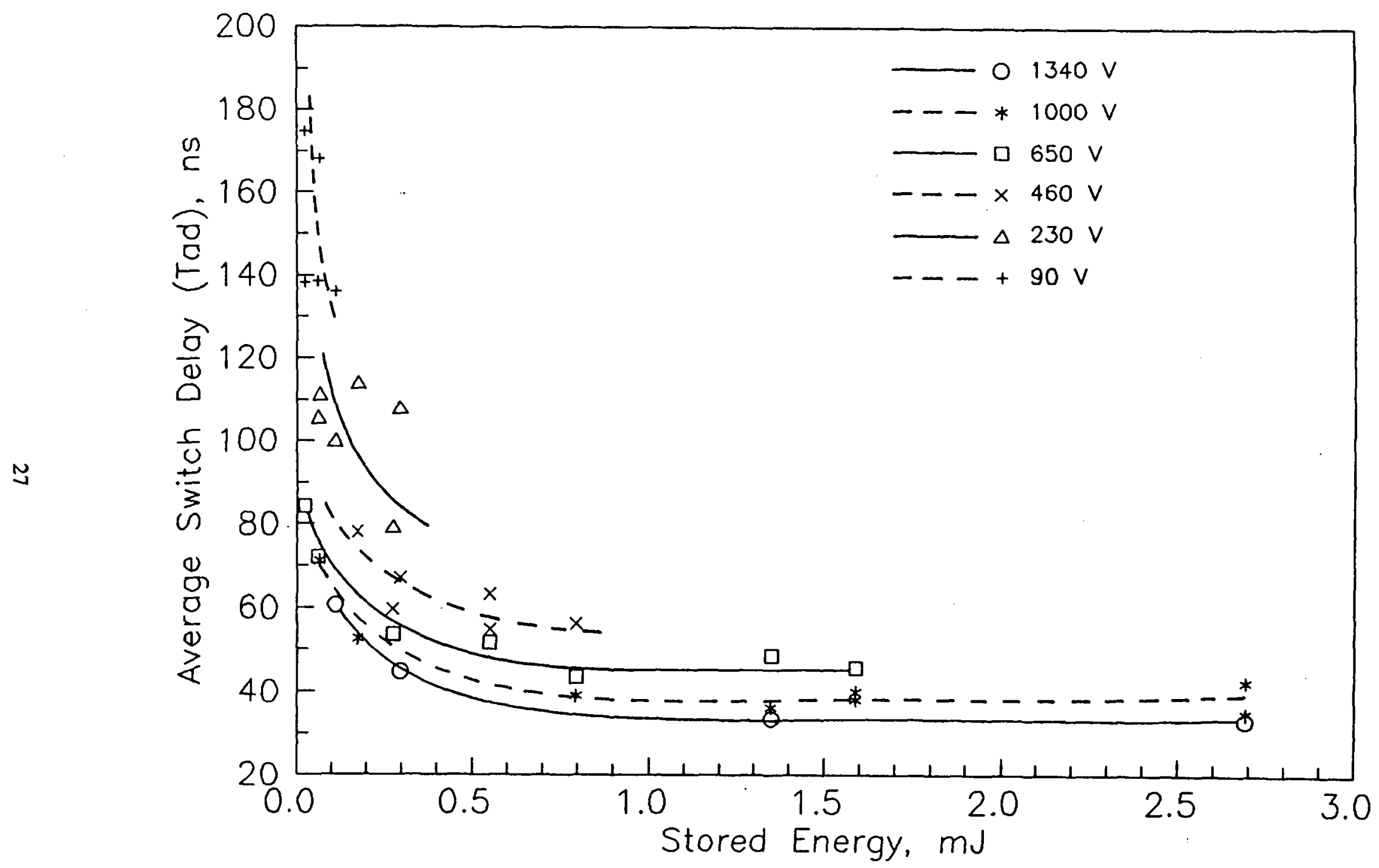

Figure 11.

Averoge switch deloy versus trigger stored energy (derived from the MC3858 data in Figure 9 using Table 1). 


\section{VARIABILITY OF SWITCH DELAY TIME}

\subsection{Variation in Switch Delay vs Average Switch Delay}

In general, the variability in switch delay time decreases with decreasing average switch delay time. This can be demonstrated using our data by plotting individual deviations in switch delay from the average switch delay, as a function of the average switch delay. We present a delay time variation plot of this type in Figure 12. Figure 12 was obtained using the 186 individual switch delay measurements shown in Figure 8 and the 36 average switch delay measurements shown in Figure 9.

In Figure 12 there are 36 groups of five square symbols, with each group of five symbols arranged in a vertical row. The 36 groups correspond to the 36 different trigger configurations investigated. The five symbols represent the five repetitions (four repetitions using MC3858-18-8942-194 and one repetition using MC3858-18-8942-193) of the switch delay measurement made for each trigger configuration. In Figure 12, we see that the variability in switch delay begins to rise very quickly for average delay times exceeding 120 nsec.

\subsection{Variation in Switch Delay vs Peak Trigger Voltage}

In order to examine the variability in switch delay time more thoroughly, we calculated the maximum measured variation in switch delay time, $\Delta T_{a d}=M a x T_{a d}-\operatorname{Min} T_{a d}$, for each of the 36 trigger configurations used. We then plotted $\Delta T_{a d}$ as a function of $V_{t}$ using the $E_{t}$ groupings described above. The resulting plot is shown in Figure 13. The solid lines in Figure 13 are meant to delineate an approximate upper bound on $\Delta T_{\text {ad }}$ for each of the coarse groups of "constant" stored trigger energy defined in the key of Figure 13. The shifting of these boundary lines downward with increasing stored trigger energy suggests that the variability of $T_{a d}$ can be decreased by increasing $E_{t}$ while maintaining $V_{t}$ fixed.

Figure 13 clearly shows that trigger voltages greater than $100 \mathrm{~V}$ are required to obtain maximum switch delay variations less than 30 ns. Decreasing $V_{t}$ to below $100 \mathrm{~V}$ leads to a catastrophic increase in $\Delta \mathrm{T}_{\mathrm{ad}}$. The limited data shown in Figure 13 suggests that increasing $V_{t}$ beyond a few hundred volts while holding stored energy constant does not strongly decrease $\Delta T_{\mathrm{ad}}$.

\subsection{Variation in Switch Delay vs Trigger Stored Energy}

The effect of increasing trigger energy can be more clearly seen by replotting $\Delta T_{\text {ad }}$ as a function of $E_{t}$. The resulting plot is shown in Figure 14. The line drawn in Figure 14 forms an upper bound on the sparse data available in the plot, and approximates the maximum $\Delta T_{a d}$ versus $E_{t}$ that one might expect to obtain if more data were available. Even though the exact position of the $\Delta T_{\text {ad }}$ curve may be tenuous, the general trend with increasing $E_{t}$ is clear. At low $E_{t}(<0.5 \mathrm{~mJ})$, substantial improvements in $\Delta T_{a d}$ may be made by raising $E_{t}$. At high $E_{t}\left(>1\right.$ or $2 \mathrm{~mJ}$ ), increasing $E_{t}$ produces only modest decreases in $\Delta \mathrm{T}_{\mathrm{ad}}$. 


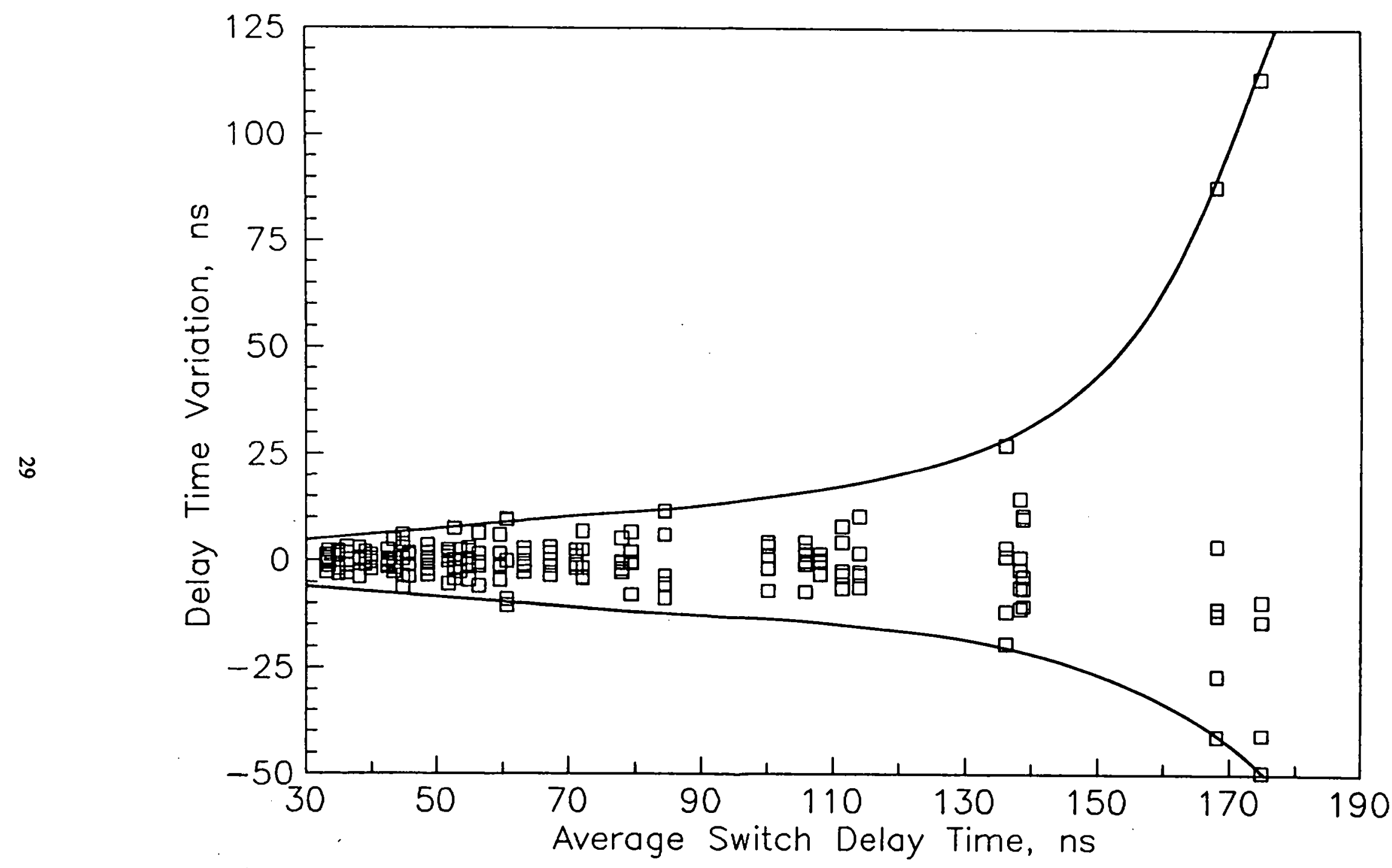

Figure 12.

Individual variations in switch delay versus average switch delay for the MC3858 sprytron (derived from the individual and overaged switch delay measurements in Figures 8 and 9). 


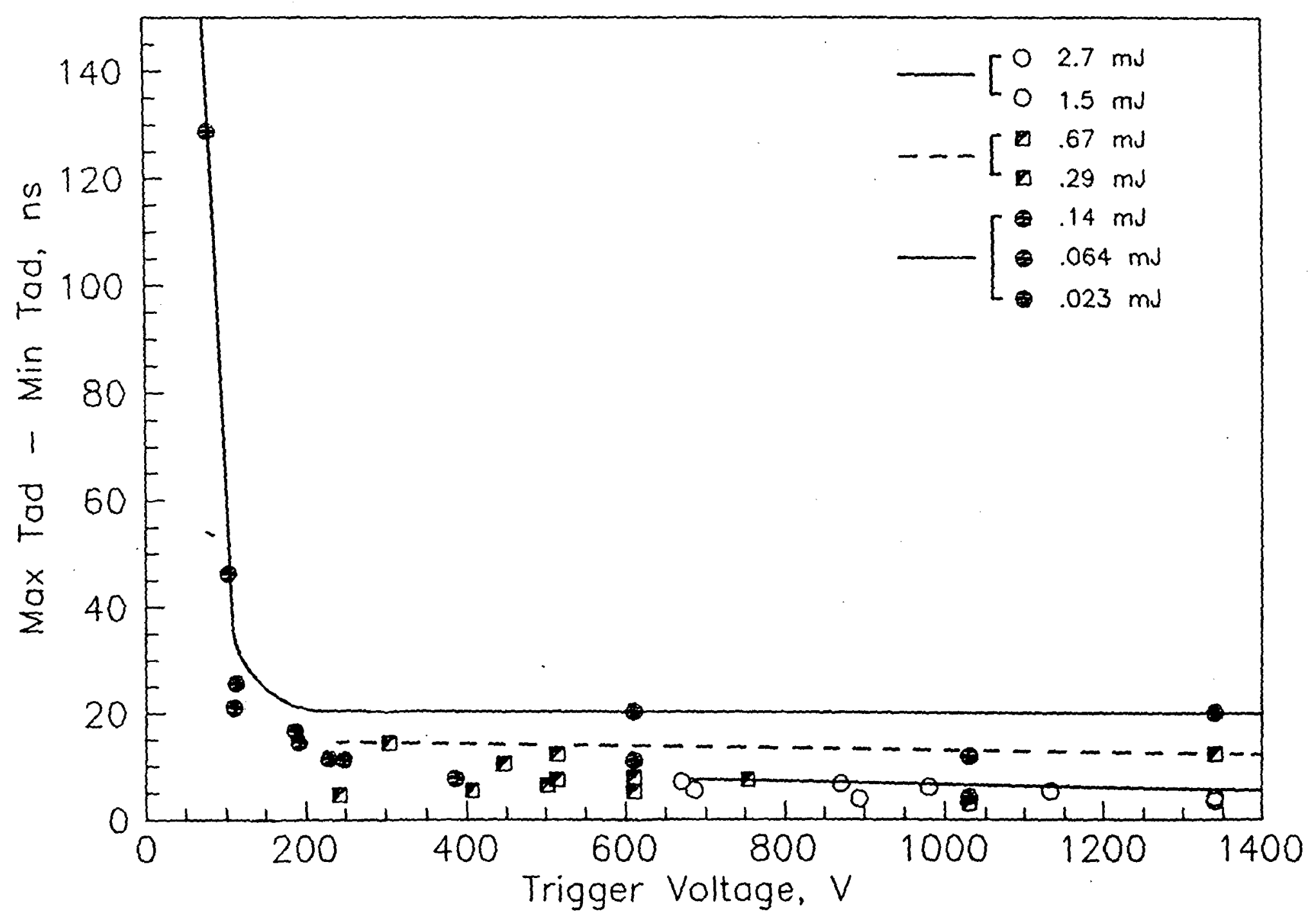

Figure 13.

Variation in MC3858 switch delay versus peok trigger voltage (derived from the MC3858 data in Figure 8 using Table 1). 


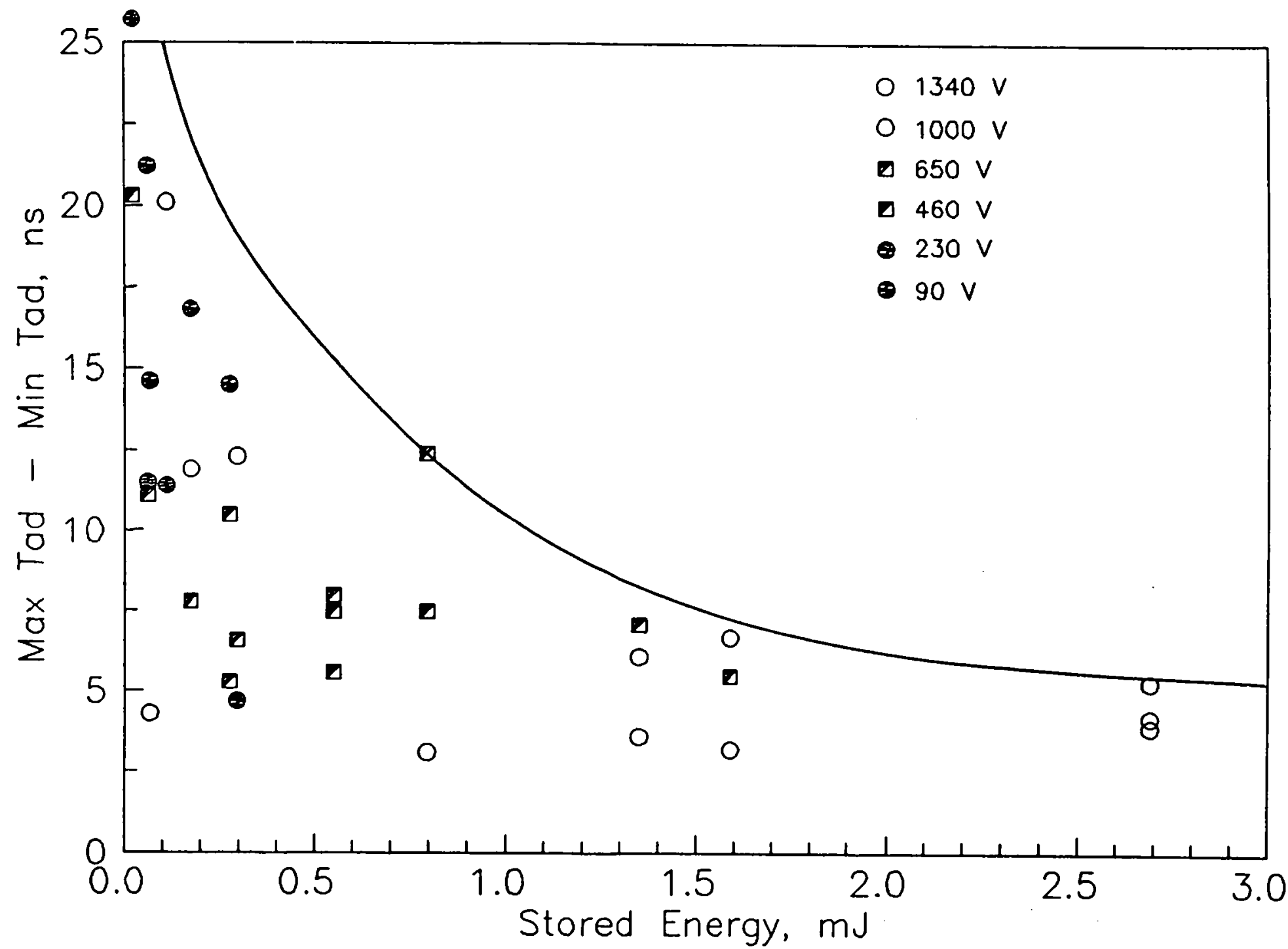

Figure 14.

Variation in MC3858 switch delay versus trigger stored energy (derived from the MC3858 dato in Figure 8 using Table 1). 
One final important comment on the present measurements of $\Delta T_{\text {ad }}$ should be made. Recall that the data shown in Figures 12-14 are based on trigger experiments involving only two MC3858 sprytrons. Thus, the results may not fully reflect variations in switch delay due to variability between tubes. General trends observed in the present data should be correct; however, the $\Delta \mathrm{T}_{\mathrm{ad}}$ observed for a large population of sprytrons may be larger than that which we present here. 


\section{TRIGGER RESISTANCE EFFECT ON SWITCH DELAY}

The effect of tube age and the accompanying increase in probe resistance on the switch delay time was evaluated for our 36 trigger configurations. This was done using tube 194 by first operating the sprytron until the trigger began to develop a high resistance. Tube 194's probe resistance began to vary erratically to high values after about three-hundred shots. Starting at shot 301 we began a new trigger matrix study of the tube. During the 36 shots required to complete the matrix the probe resistance varied between $0.4 \mathrm{k} \Omega$ and $10 \mathrm{M} \Omega$. The individual switch delay measurements obtained for this aged tube are shown by the symbols in Figure 15. The solid line in the figure represents the upper and lower bounds of the average switch delay for a sprytron with a low resistance trigger (these boundary lines are taken from the measurements presented in Figure 9). Clearly, many of the high probe resistance switch delay measurements deviate substantially from the previous results obtained at low probe resistance.

In a point-by-point comparison of the 36 configurations examined during shots $301-336,13$ of the shots had switch delay deviations larger than expected, based on the variability of deviations observed at low probe resistance. Examination of the overvoltage gap waveforms taken during each of these shots indicates that the high resistance probe had a nominal breakdown voltage of $400-600 \mathrm{~V}$. It appears that when the probe resistance is high, the probe acts as a second overvoltage gap with a breakdown voltage of about 400-600 V (at least in this case).

If the peak voltage initially applied to the trigger is greater than the high-resistance-probe breakdown voltage, the probe flashes over immediately, and switch delay is relatively unaffected. If the peak trigger voltage is less than the high-resistance-probe breakdown voltage, the probe acts like a second overvoltage gap in series with the first. The trigger and filtering capacitors are connected in parallel once the first gap breaks down, and they continue on a new voltage ramp following breakdown of the first gap until the breakdown voltage of the second gap is reached. The additional time required to ramp up to the breakdown voltage of the high-resistance probe accounts for most of the excess switch delay time observed here. These results suggest that one potential advantage of using a high peak trigger voltage is the additional immunity it will provide against increases in switch delay as the trigger probe resistance begins to increase with age. 


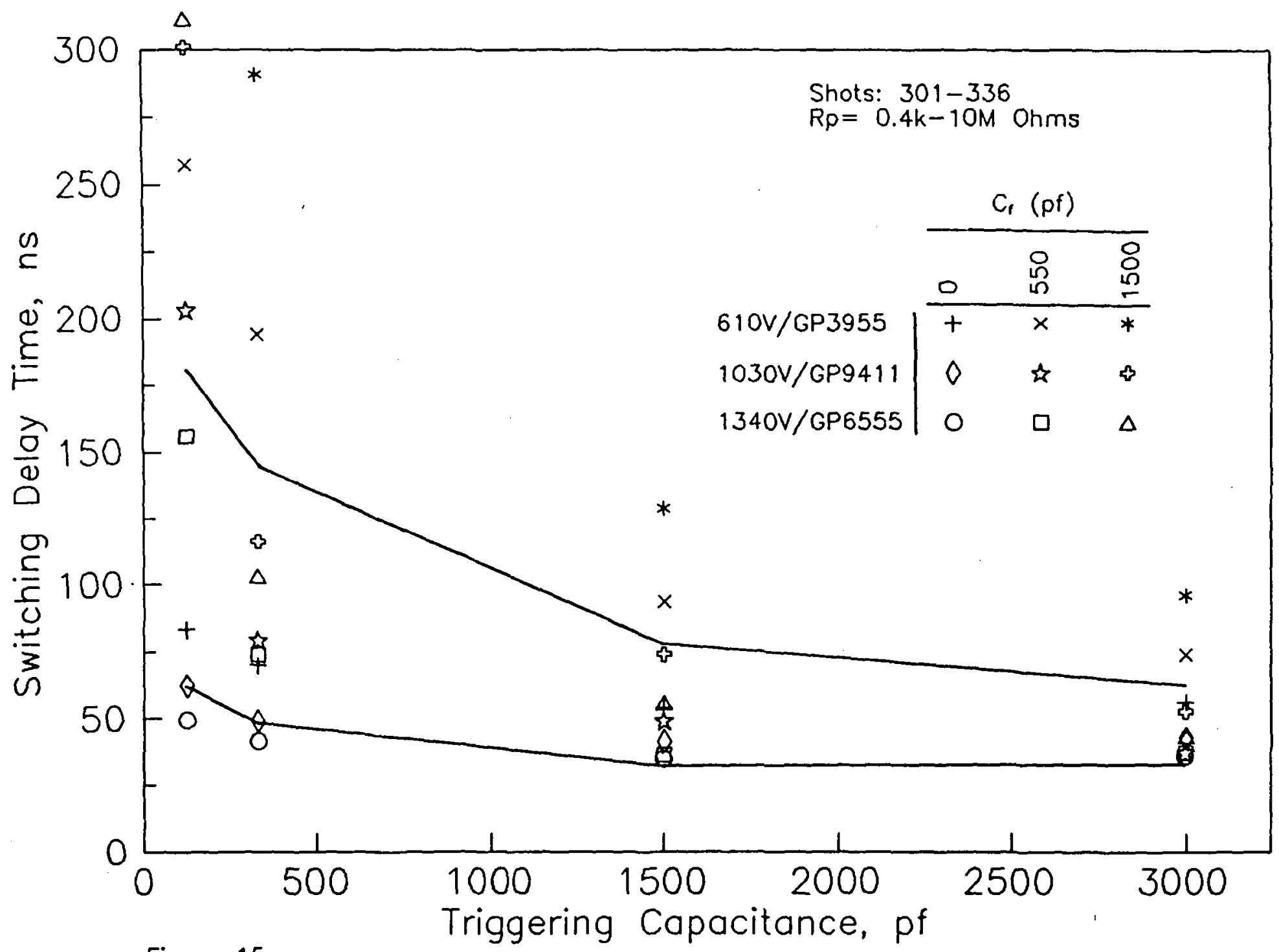

Figure 15.

Comparison of the switch delays for a MC3858 sprytron with a probe resistance varying up to 10 MOhms to the overage switch delays of a normal MC3858. Symbols represent individual deloys meosured at high $R_{p}$. Solid lines bound the space containing the average delays measured at normal $R_{p}$ (from Figure 9 ). 


\section{CDU BIAS EFFECT ON SWITCH DELAY}

We concluded the present series of experiments by examining whether or not the voltage applied to the sprytron main gap has any effect on the switch delay time. Tube 193 was used for these measurements. The bias was reduced from the $2420 \mathrm{~V}$ used in the above experiments to $725 \mathrm{~V}$ in order to look for a bias effect on switch delay. For this experiment, we did not use the full 36 trigger configuration shown in Table 1. Here, we used only the GP6555/1340V gap and the GP3955/610V gap.

The switch delay measurements for the 12 trigger configurations corresponding to the GP6555/1340V gap are shown as symbols in Figure 16. The solid line in the figure represents the upper and lower bounds of the average switch delay for a sprytron operated at $2420 \mathrm{~V}$ using a GP6555/1340V gap (these boundary lines are taken from the measurements presented in Figure 9). While some of the measurements made at $725 \mathrm{~V}$ fall outside of the space bounded by the average delays, a point-by-point comparison of the observed deviations with the expected likely variation (shown in Figure 12) shows that none of measured delays at $725 \mathrm{~V}$ are significantly different from those measured at $2420 \mathrm{~V}$.

Switch delay measurements for the 12 trigger configurations corresponding to the GP3955/610V gap are shown as symbols in Figure 17. The solid line in the figure represents the upper and lower bounds of the expected average switch delay for a sprytron operated at $2420 \mathrm{~V}$ using a GP3955/610 V gap (again, these boundary lines are taken from the measurements presented in Figure 9). Once again, a point-by-point comparison was made to determine if any of the observed deviations were significant relative to measurements made at $2420 \mathrm{~V}$. Only one point ((330 pf, $236 \mathrm{~ns})$ in Figure 17) deviated significantly from previous measurements made at $2420 \mathrm{~V}$. $E_{t}$ and $V_{t}$ for this point are $0.023 \mathrm{~mJ}$ and $113 \mathrm{~V}$, respectively.

On the whole, these results suggest that there is little, if any, effect of sprytron bias on switch delay time under most trigger conditions of interest. There is some scant evidence (the one significant point in Figure 17) that at very low trigger voltage and trigger energy the sprytron bias voltage may be coupled to the switch delay time. Alternatively, since we know that the variation in switch delay becomes highly variable near trigger voltages of 100 $V$ (see Figure 13), and since the one deviating measurement was taken at a peak trigger voltage $(113 \mathrm{~V})$ very near this precipice, the one deviation observed above may not, in fact, actually be due to a bias voltage affect. 


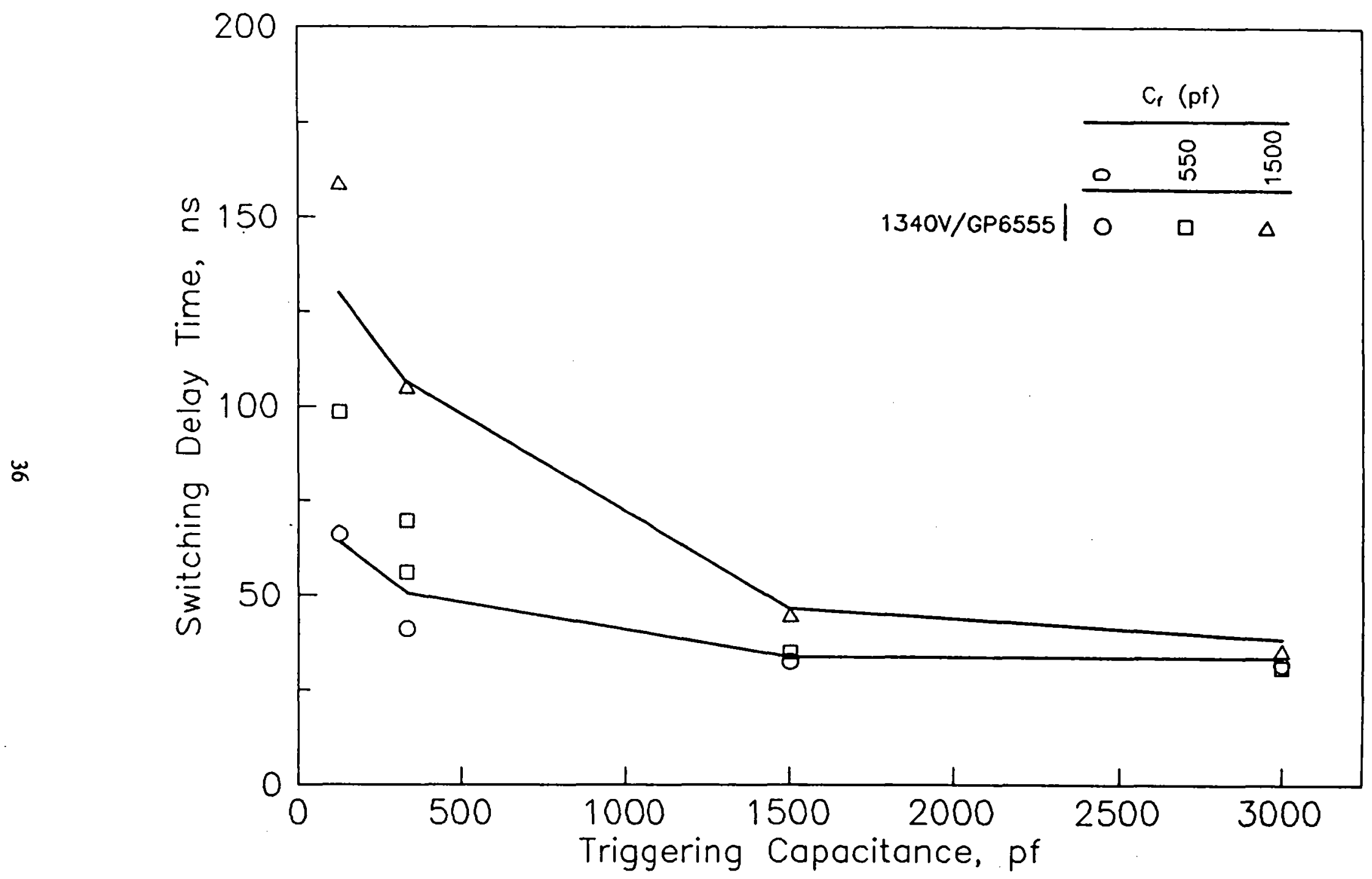

Figure 16.

Comparison of switch delays for a MC3858 sprytron operated at a bios of $725 \mathrm{~V}$ and a bias of $2420 \mathrm{~V}$. Symbols represent individual delays measured at $725 \mathrm{~V}$. Solid lines bound the spoce containing the average delays meosured at $2420 \mathrm{~V}$. All meosurements used the 1340V/GP6555 gap in the trigger circuit. 


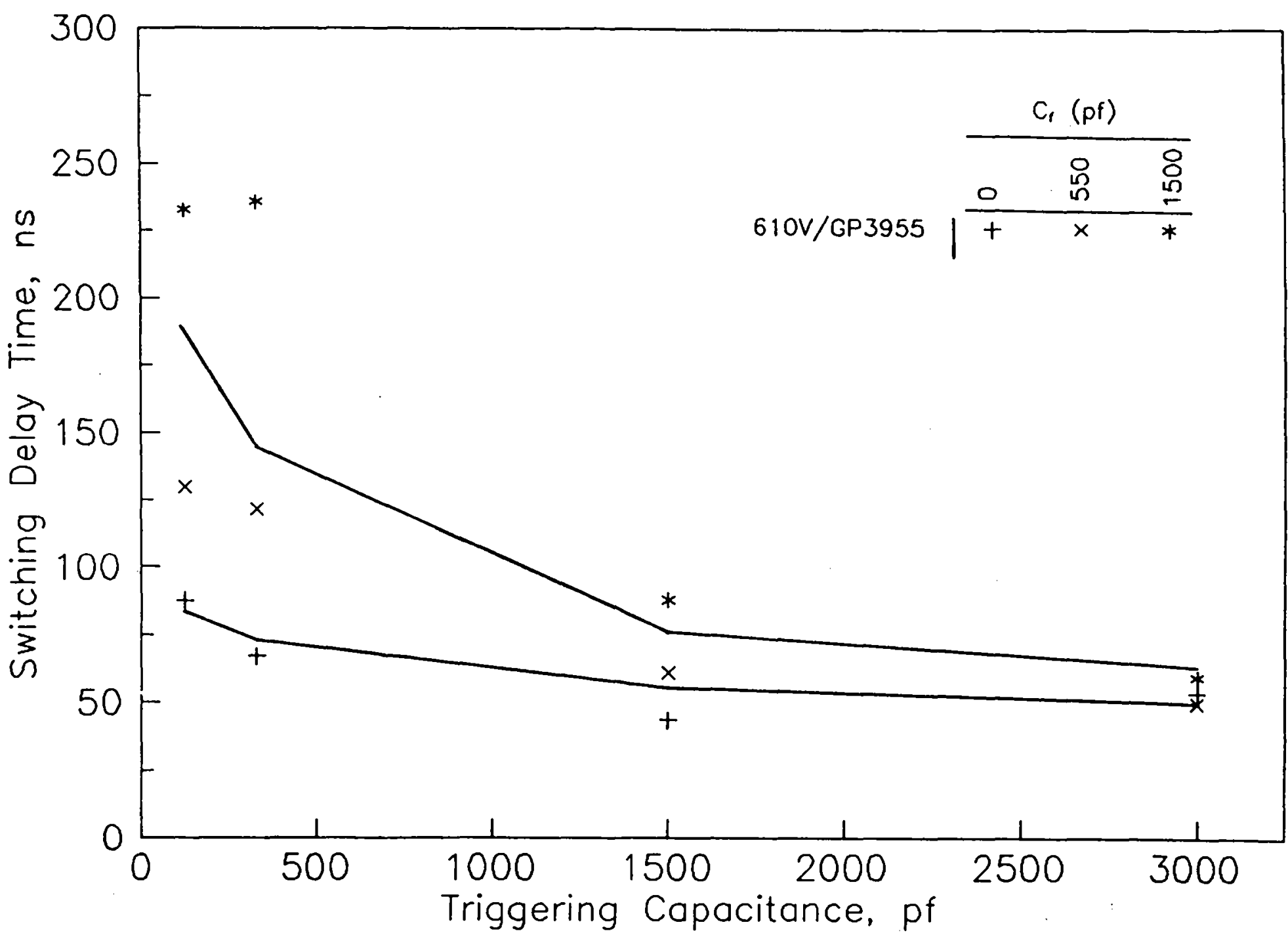

Figure 17.

Comporison of switch delays for a MC3858 sprytron operated at a bios of $725 \mathrm{~V}$ and a bias of $2420 \mathrm{~V}$. Symbols represent individual delays meosured at $725 \mathrm{~V}$.

Solid lines bound the spoce containing the average delays meosured of $2420 \mathrm{~V}$. All meosurements used the $610 \mathrm{~V} / \mathrm{GP} 3955 \mathrm{gop}$ in the trigger circuit. 


\section{CONCLUSIONS}

The effect of varying triggering capacitance, overvoltage gap breakdown voltage, filtering capacitance, sprytron age/trigger resistance, and CDU bias voltage on switch delay time $\left(T_{\text {ad }}\right)$ was evaluated for the MC3858 sprytron.

Triggering capacitance, $C_{t}$, filtering capacitance, $C_{f}$, and overvoltage gap breakdown voltage, $V_{b}$, taken together, were found to determine two fundamental trigger parameters: stored trigger energy, $E_{t}$, and peak trigger voltage, $V_{t}$. The effect of $E_{t}$ and $V_{t}$ on switch delay was determined by testing two MC3858 sprytrons using 36 different trigger configurations. We found that the average switch delay is both relatively insensitive to $E_{t}$ above $0.5 \mathrm{~mJ}$ and relatively insensitive to $V_{t}$ above $800 \mathrm{~V}$. Decreasing either $E_{t}$ or $V_{t}$ below these values leads to significant increases in the average switch delay time.

We also found that the variation in switch delay is about 25 ns or less for essentially any $V_{t}$ greater than $\sim 100 \mathrm{~V}$. Decreasing $\mathrm{V}_{\mathrm{t}}$ below $100 \mathrm{~V}$ leads to a catastrophic rise in the variation of switch delay (to $100 \mathrm{~ns}$ or more). Above a $\mathrm{V}_{\mathrm{t}}$ of $\sim 100 \mathrm{~V}$, the variation in switch delay is primarily a function of $E_{t}$. Increasing $E_{t}$ from $0.1 \mathrm{~mJ}$ to $2.7 \mathrm{~mJ}$ appears to produce a monotonic decrease in the variability of switch delay from $25 \mathrm{~ns}$ to $6 \mathrm{~ns}$. We again state that these variations were measured using only two sprytron units. Thus, the switch delay time variability for a large population of sprytrons may be significantly greater than reported here.

The effect of high trigger resistance on switch delay time was determined by first operating a sprytron until the trigger began to vary in resistance between $0.4 \mathrm{k} \Omega$ and $10 \mathrm{M} \Omega$. Switch delays were then measured using the 36 different trigger configurations mentioned above. The high resistance trigger was found to behave as a second overvoltage gap in series with the original gap. For these experiments, the high resistance trigger typically underwent high voltage breakdown between 400 and $600 \mathrm{~V}$. Trigger configurations with an initial $V_{t}$ higher than the trigger breakdown voltage performed with their normal switch delay time. Trigger configurations with an initial $V_{t}$ lower than the trigger breakdown voltage had increased switch delay times. The increase in switch delay is largely due to the additional time required to ramp up to the breakdown voltage of the high resistance trigger.

The effect of sprytron bias on switch delay time was evaluated by performing a series of similar sprytron operations at bias voltages of both $2420 \mathrm{~V}$ and $725 \mathrm{~V}$. For most of the trigger configurations studied here, there was no significant change in switch delay time when the sprytron bias was decreased from $2420 \mathrm{~V}$ to a relatively low operating value of $725 \mathrm{~V}$. 


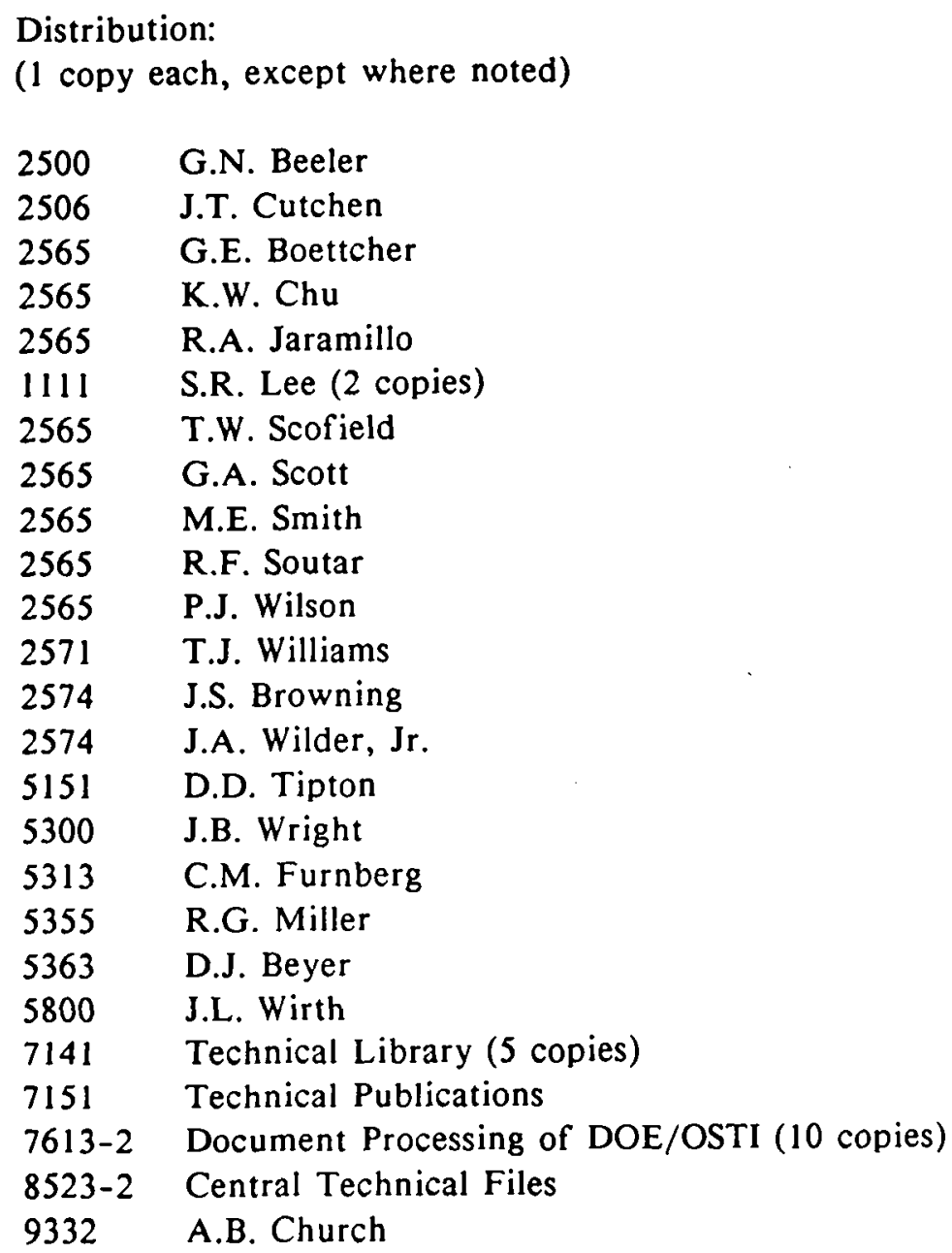


THIS PAGE INTENTIONALLY IEET BLANTS 